\title{
Galen's Pathological Soul: Diagnosis and Therapy in Ethical and Medical Texts and Contexts*
}

\author{
P. N. Singer
}

Much has been written on Galen's theory of the soul or psychē: its sources and complexities, the variations in its exposition; the nature of the ethical and physiological accounts which it offers; the extent to which these can be understood as belonging within a single model of explanation. The topic continues to provide a complex ongoing discussion. ${ }^{1}$

* I gratefully acknowledge the support of the Alexander von Humboldt Stiftung and the Wellcome Trust, both of which supported my research during the initial work on this paper, the latter also during its completion. I am also grateful to the participants at the 2014 Berlin conference, 'Mental Diseases in the Ancient World', for discussion and feedback, and especially to Chiara Thumiger for inviting me to be a part of the project.

1 See Gill, C. (2010) Naturalistic Psychology in Galen and Stoicism and Singer, P. N. (ed.) (2013) Galen: Psychological Writings, for recent analysis of the central 'psychological' texts and discussion of the secondary literature, and the latter also for further bibliography in this area (listed e.g. at 5 n. 8). As noted there, recent scholarly work on Galen's psychology or soul/ mind theory has tended to focus on his philosophical rather than his medical works, and has predominantly been concerned with philosophical analysis and/or Galen's philosophical affiliations.

But a wider range of texts is taken into account by, for example, García Ballester, L. 'Soul and Body, Disease of the Soul and Disease of the Body in Galen's Medical Thought'. in Manuli, P and M. Vegetti (1988) Le opere psicologiche di Galeno, 117-52; Manuli, P. 'La passione nel De placitis Hippocratis et Platonis', ibid., 185-214; and, more recently, by: Jouanna, J. 'Does Galen Have a Medical Programme for Intellectuals and the Faculties of the Intellect?' in Gill, C et al. (2009) Galen and the World of Knowledge, 190-205; id., 'The Typology and Aetiology of Madness in Ancient Greek Medical and Philosophical Writing', in Harris, W. V. (2013) Mental Disorders in the Classical World. Columbia Studies in the Classical Tradition 38, 97-118; Boudon-Millot, V. 'What is a Mental Illness, and How Can It Be Treated? Galen's Reply as a Doctor and Philosopher', ibid., 129-45; Holmes, B. 'Disturbing Connections: Sympathetic Affections, Mental Disorder, and the Elusive Soul in Galen', ibid. 147-76; von Staden, H. 'Body, Soul, and Nerves: Epicurus, Herophilus, Erasistratus, the Stoics, and Galen, in Wright, J. P. and Potter, P. (200o) Psyche and Soma, 79-116 and 'The Physiology and Therapy of Anger: Galen on Medicine, the Soul, and Nature', in Opwis, F. and Reisman, D. (2011) Islamic philosophy, science, culture, and religion, 63-87; and Singer, P. N. 'The Essence of Rage: Galen on Emotional Disturbances and their Physical

(C) P.N. SINGER, 2018 | DOI 10.1163/9789004362260_016

This is an open access chapter distributed under the terms of the prevailing CC-BY-NC-ND License at the time of publication. 
The present chapter, while drawing and building upon those discussions, has a narrower and more specific aim in view. My central focus here is how Galen both categorizes, and attempts to treat, the pathe of the psychē. And the recourse to Greek terms right at the outset is deliberate and unavoidable: in question here are - in English - the 'passions of the soul', on the one hand, and 'mental illness' or 'impairment', on the other. Also at stake are the questions, whether these two conceptions do, indeed - in Greek or in English-involve separate discourses and practical interventions; and, to the extent that they are separate, what is their relationship, and their relative prominence and theoretical or practical power, in the Galenic texts.

The chapter thus attempts an analysis of Galen's variety of approaches to the pathe of the psychē-an analysis of what Galen does (or purports to do) in his capacity as philosopher, medical theorist, psychotherapist, psychiatrist, even 'life coach'. But the more complex, theoretical question - the analysis of Galen's 'models of the soul' - underlies this pathological and therapeutic one: this will therefore be addressed first, inasfar as necessary before turning to practical or clinical matters, and in particular inasfar as relevant to the Galenic understanding(s) of pathos in this context. Further, this 'variety of approaches' should not just be seen as a set or recommendations which can be extracted from his texts and then evaluated in isolation from those texts; rather, some account is required of the nature, intent, or genre of the writings in which they appear. That is to say, the statements which we will be considering occur in widely differing works; and, in order to understand what our different extracted texts are telling us about Galenic therapy, it will be important to consider their different theoretical levels, intended audiences or discourse groups, and predecessors or competitors, as implied by their context and genre. ${ }^{2}$ Through

Correlates', in Seaford, R. et al. (2017) Selfhood and the Soul, 161-96. See also Schiefsky, M. 'Galen and the Tripartite Soul', in Barney et al. (2012) Plato and the Divided Self, 331-49; Hankinson, R. J. 'Partitioning the Soul: Galen on the Anatomy of the Psychic Functions and Mental Illness', in Corcilius, K. and Perler, D. (2014) Partitioning the Soul: Debates from Plato to Leibniz, 85-106. There are, further, important articles by Ahonen, M. (2017) 'Galen on Sexual Desire and Sexual Regulation', Apeiron 50.4, 449-81 and Havrda, M. (2017) 'Body and Cosmos in Galen's Account of the Soul', Phronesis 62, 68-89, both of which unfortunately appeared too late to be taken into account in the present paper.

2 This is not the place for a comprehensive analysis of the various genres and intended audiences of Galen's writings, nor would that be a straightforward enterprise. The following may suffice as a first approximation in relation to the works which we shall especially consider. Affections and Errors of the Soul (Aff. Pecc. Dig. 1 and 2), Freedom from Distress (Ind.) and Character Traits (Mor.) are ethical works, so characterized by Galen himself in My Own Books (Lib. Prop. 15 [12] (XIX.45 = 169,13-17 Boudon-Millot)), the former two represented as 
this consideration of different texts and contexts, then, the chapter aims to shed light on the broader question of the nature of, and relationship between, medical and philosophical therapy of the soul.

The chapter thus falls into four parts: the first gives a summary of the problem of the different models of psychological explanation within Galen's work; the second gives an overview of the most important texts bearing directly on Galenic 'therapy of the soul', in its full variety of senses, philosophical and medical; the third attempts an evaluation of these texts in relation to their genre and the context of their discourse; and the fourth presents a summary, and some concluding considerations, in relation to our findings.

\section{Models of Psychological Explanation in Galen}

We may best approach our summary analysis of this problem by considering the question: what is a pathos of the soul for Galen? The word pathos, usually translated into English as "affection" or "passion", and of course familiar in modern languages from aesthetic, emotive and medical terms in common use (pathos, pathetic, pathology), is a central term in the Graeco-Roman ethical—but, as we shall shortly see, also medical ${ }^{3}$ — discourse, referring, to

occasional compositions arising from an individual enquiry and/or debate:Aff.Pecc. Dig.1.1(v.1 $\mathrm{K} .=3,4-7$ de Boer), Ind. 1 (2,3-5 BJP); their closest parallels within Graeco-Roman popular philosophical writing are helpfully explored by Gill, Naturalistic Philosophy, 205-32. Both The Soul's Dependence on the Body (QAM) and The Doctrines of Hippocrates and Plato (PHP) are works "pertaining to Plato's philosophy", Lib. Prop. 16 [13] (XIX.46 = 170,14-171,5 BoudonMillot), both with clear polemical aims in attacking other philosophers and persuading an intellectual audience of certain theoretical propositions. The Therapeutic Method (MM) and Affected Places (Loc. Aff.) are among the major medical works (but on this category see further below). De sanitate tuenda (San. Tu.) is the magnum opus on daily regime, which Galen claims to be-in explicit contradistinction to $M M$ - aimed at a wider, 'medicine-friendly' but not specifically medical, audience, San. Tu. 4.5 (VI.269 K. = 118,31-33 Koch). Prognosis (Praen.) is the most striking example of a work of self-advertisement, though there are elements of that throughout Galen's oeuvre, including in the very voluminous and learned Hippocratic commentaries; these latter (see again further below) seem to be intended for an audience of medical students or persons with serious medical and/or philological interests.

3 Cicero has provoked surprise and rebuke in some quarters for suggesting (at Tusc. 3.7; cf. ibid. 4.10) that the Latin word morbus would be a literal translation of the Greek pathos-albeit one inappropriate to its use in relation to the soul. Yet the medical use of the term to mean illness or impairment is well established from Hippocratic writings — one of which, indeed, is entitled Peripathōn - onward, and the usage is not only employed but explicitly discussed by Galen: see De symptomatum differentiis 1 (VII.44-45 K. = 200,9-202,12 Gundert) both for an 
put it in the simplest and least doctrinally loaded way possible, to something that has gone wrong, to an undesirable state. The answer to the above question, in fact, is given quite clearly in the short ethical work Affections and Errors of the Soul, and in similar terms in The Doctrines of Hippocrates and Plato, especially books 4 and 5 . A pathos of the soul is a state or event whereby one of the two non-rational (aloga) parts of the soul, the desiderative or the spiritedthe two may, in fact, be referred to jointly as the pathetikon-overrides the judgement of the rational part, leading the person to inappropriate actionaction, typically, which manifests an excessive or uncontrolled level of greed, lust or anger. ${ }^{4}$

This understanding of pathos is rooted in the clear distinction made by Galen between those things which may go wrong with the non-rational part of the soul - which are characterized as pathos - and those which may go wrong with the rational, which come rather under the heading of hamartēma ("error"): mistakes of judgement, errors on matters of fact, false reasoning. The distinction is fundamentally rooted in the Platonic division of the soul into rational and non-rational forms or parts-even if this Platonic division, and the related notion of pathos, are (we would suggest in a fuller account) read by Galen with post-Aristotelian and Stoically-influenced eyes. At any rate, the distinction between the domains of rational and non-rational is clear, and it is clear, too, that "error" (hamartēma) falls within the former domain, while "affection" (pathos) falls within the latter. ${ }^{5}$ The non-rational parts of the soul do not make hamartēmata; and the rational part is not subject to pathos (except, of course, in the sense that it may come to be overwhelmed by an out-ofcontrol non-rational part when a state of pathos obtains: that is precisely how pathos works). But while there are, in this scheme, characteristic pathe of each of the non-rational parts of the soul, there is, by definition, no such thing as a pathos specific to the rational.

What role can there possibly be, then, for Galen, for a pathos of the rational part of the soul — the part which is, according to his somatic understanding

affirmation that the term pathos is in common Greek use to refer to diseases and for a more precise 'proper' definition (it is a broader term, covering any kind of alteration or 'being affected', e.g. in the process of perception, but certainly can include disease); and the similar discussion beginning at Loc. Aff. 1.3 (VIII.32 K. = 262,8-17 Gärtner).

4 For more detailed discussion of the account of pathos in Affections and Errors of the Soul, and its relationship with the philosophical tradition, see Singer, Psychological Writings, esp. 207-28.

5 See in particular Aff. Pecc. Dig. 1.1 (v.3 K. = 3,20-4,5 de Boer) for the insistence on this distinction, which informs the whole structure of the work. 
of the Platonic tripartite soul, located in the brain? The answer, paradoxical though it may seem according to the model just outlined, is: a very considerable one. For the rational soul, understood as the soul's leading-faculty, the hègemonikon, is subject to a whole range of illnesses or impairments-impairments which arise from physical conditions of the brain, or affecting the brain;

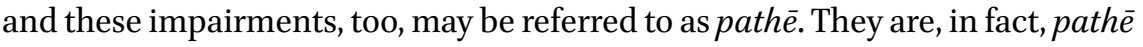
of the rational part of the soul. ${ }^{6}$ But, in spite of the apparent equivalence, for Galen, of the hègemonikon with the Platonic logistikon or reasoning-faculty, vocabulary referring to this kind of pathos is not the philosophical-ethical one of error, false opinion, or failure to reason logically; rather, it is a strictly medical vocabulary-melancholia, phrenitis, mania, paraphrosyne- - a vocabulary which is as absent from Galen's ethical works as the terminology of hamartēma and correct reasoning about the goal of life is absent from the medical discourse. ${ }^{7}$

Indeed, in one passage in Affected Places, a distinction between impairments of the rational and those of the non-rational leads to a terminological opposition between hègemonikai, "of the leading-part" and èthikai, "ethical". (To be

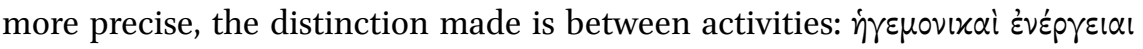

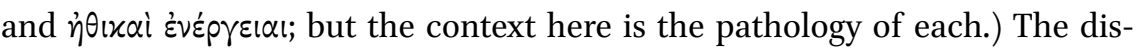
tinction seems of great interest, yet the passage is ultimately tantalizing. On the one hand, the equation of non-rational with "ethical" seems to suggest that the cure of the latter belongs in the realm of philosophical therapy-the kind covered by Affections and Errors of the Soul, Freedom from Distress and Character Traits: these works, we have seen, are defined by Galen as related to "ethical" philosophy; and the Greek title of the last one is, after all, Peri èthōn. ${ }^{8}$

6 The term pathos is used very extensively in Affected Places to refer to impairments or "affections" throughout the body, including those of the brain and rational capacity; see e.g. 3.6

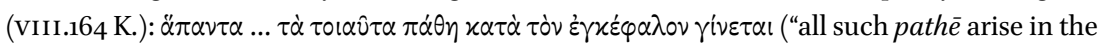
brain"); and the term 'pathē of the rational' ( $\tau \dot{\alpha} \tau \circ \hat{\imath} \lambda \circ \gamma(\sigma \tau \iota x \circ \hat{v} \pi \dot{\alpha} \theta \eta$ ) is used explicitly at 3.6 (vıII.16o K.). Cf. Julien Devinant's discussion of Galenic usage in this area, above, esp. 202-4.

7 One should perhaps make the qualification that mania is used in relation to anger at Aff. Pecc. Dig. 1.5 (V.22 K. = 16,5.15 de Boer); but the language is hyperbolic and the point precisely that certain extreme forms of anger seem to take one into this different realm.

8 A further problem is touched upon by this very equation of 'non-rational with 'ethical': in Mor. Galen explicitly addresses the question whether the category of etthos arises only in the non-rational, and suggests that on the contrary there is in some cases a rational component in éthos too. (The text of Mor. is problematic, available only through an Arabic summary and a number of further quotations in other Arabic and Hebrew sources; the source suggesting the above interpretation is in one of these latter: see Singer, Psychological Writings, 174.) 
Yet the way in which the argument is developed, or rather not developed, is inconclusive.

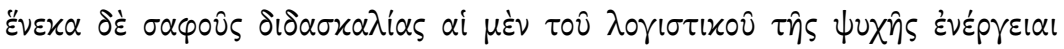

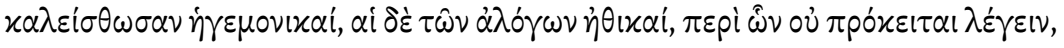

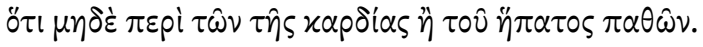

In the interests of clarity of exposition, let us call the activities of the rational in the soul "leading" and those of the non-rational ones "ethical" (or, "character-based"); the latter are not our subject now — as indeed the impairments of the heart or of the liver are not our subject either. ${ }^{9}$

LOC. AFF. 3.6 (VIII.163 K.)

The impairments (n.b.: pathē) of the non-rational soul are ruled out of the discussion here-by the same token as those of the heart and the liver. This seems to leave it open whether Galen is saying that a full discussion of impairment of the non-rational soul would, indeed, involve the heart and the liver (the correlated bodily locations of the two non-rational drives) or rather that, since ethical, they are best left to the ethical discourse (or, indeed, have already been dealt with there). ${ }^{10}$ What is of key significance to our discussion here is that neither of these possibilities is further pursued or clarified; the present passage, indeed, stands as a very neat summation of our problem: Galen's apparent creation of different frameworks within which to address the 'mental', and his unhelpfulness in clarifying the relationship between them.

What is clear, however, is the existence of a different vocabulary and theoretical approach, for the pathe of the hègemonikon in the medical context and for the ethical discourse. We seem to have a completely different type of account, or model of explanation — the medical model—sitting alongside the ethical-philosophical model in Galen's oeuvre, while confusingly using some

$9 \quad$ Here, and throughout except where otherwise stated, the translation is my own.

10 According to the dates proposed by Nutton (in Singer, Psychological Works, 45-48) for the extant ethical works, all were composed after the death of Commodus in $192 \mathrm{CE}$, and in the case of Freedom from Distress very soon after that; the others would belong either in the reign of Septimius Severus - the same broad period to which Affected Places is attributed - or possibly later. (But cf. Boudon-Millot and Jouanna, Ne pas se chagriner, lx, arguing for an earlier date for Affections and Errors.) The question of relative dates of Galenic works is in any case a thorny one (cf. Singer, Psychological Writings, 34-41), particularly in view of the probability that many had more than one phase of composition. It is at least possible that the sentence here contains an implication that the 'ethical' subject has already been dealt with. 
of the same technical vocabulary-most notably, the word pathos. We have ethically-conceived pathe of the soul, specifically of the non-rational soule.g. greed, envy, lust, quickness to anger-in the ethical works; and we have medically-conceived pathe of the soul, or at least pathe involving the impairment of psychic capacities, including of the rational capacity-e.g. derangement, hallucination, madness, melancholy —in the medical works. These are, it seems, two quite separate discourses, representing different conceptions of the soul and belonging to different intellectual traditions.

And, just as the ethical pathe psychēs are individuated and related to different parts or capacities of the soul in the ethical contexts already mentioned, the pathe understood in terms of the affection of the brain or malfunction of its activities-for which I shall henceforth use the term 'medical psychic impairments' - are also distinguished and categorized, in various medical works. To gain a coherent overall picture of these medical psychic impairments, however, is not the simplest matter: Galen addresses the issue in different contexts, using different principles of individuation, and also mentioning different collections of 'disease entities' in those different contexts.

A detailed account of what Galen says about the medical psychic impairments - which would cover a wide range of entities (anoia, apoplēxia, epilēpsia, karos, kōma, lèthargos, mania, melancholia, mōria, mōrōsis, parakopē, paranoia, paraphrosynē, phrenitis, spasmos) and involve analysis of a huge number of texts, including passages in a range of the Hippocratic commentaries, as well as the detailed, complex (and by no means obviously congruent) discussions in De symptomatum causis, De symptomatum differentiis and Affected Places - would be beyond my scope here. I confine myself to the briefest possible summary of this material.

The third chapter of De symptomatum differentiis seems to present itself as the locus classicus for Galen's typology of mental illness in the medical sense. It specifically individuates what seem the most relevant categories-that of damage to psychic, as opposed to natural, activities ( $\psi v \chi w \alpha \alpha i$ as opposed to

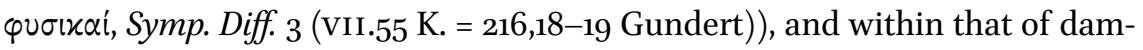
age to those "of the leading part" (henceforth, "hegemonic"), as opposed to

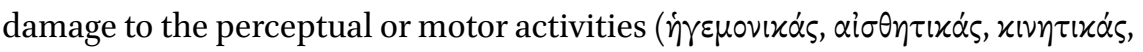
ibid. VII.55 K. $=216,19-20$ Gundert), as well as apparently offering a full and clear categorization of items within those categories.

Yet, a note of caution needs to be sounded, as to how context-specific and ad hoc, as opposed to comprehensive and fully thought-out, such Galenic typologies are.

A tabular summary of the outcome of the discussion of De symptomatum differentiis may be helpful, both in outlining Galen's thought in this area and in 
Area of hègemonikon affected

\begin{tabular}{|c|c|c|c|}
\hline & phantastikon & dianoētikon & mnēmoneutikon \\
\hline \multicolumn{4}{|l|}{ Level of impairment: } \\
\hline 'paralysis' & karos, katalepsis & anoia & \\
\hline (oiov $\pi \alpha \rho \alpha ́ \lambda v \sigma i \varsigma \tau i \varsigma)$ & & & loss of memory \\
\hline faulty motion & paraphrosynē & mōria, mōrōsis & during and after \\
\hline 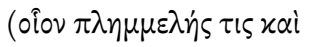 & & & illness \\
\hline \multicolumn{4}{|l|}{ 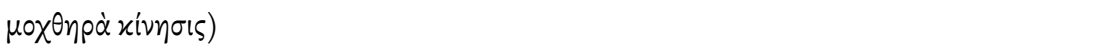 } \\
\hline incomplete or weak & kōmata, lēthargoi & paraphrosynē & \\
\hline motion & & & \\
\hline 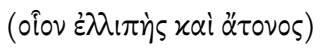 & & & \\
\hline
\end{tabular}

Symp. Diff. 3, VII.6o-62 K. = 224,9-226,22 Gundert

identifying some of the problems of interpretation. To give a little context: before arriving at the distinctions mentioned, Galen, the lover of subdivison, has cut the category of symptoma - itself situated in a complex position in relation to other pathological terms (Symp. Diff. 1, VII.42-53 K. $=198-214$ Gundert) into three: diatheseis of the body; impairments of activity; things that follow from both in terms of excretions, etc. (ibid. 2, VII.53 K. $=214,4-9$ Gundert). It is within the second of those categories that the distinctions of activity belong; it must be specified, further, that damage (blabē) to an activity may be understood in three ways: as total loss of the activity (here, paralysis); as faulty operation; or as weak or incomplete operation. Moreover, the hegemonic subsection of the psychic activities itself admits of a further threefold division: that which interprets perceptions (phantastikon), that which reasons (dianoettikon) and that of memory (mnēmoneutikon) (ibid. 3, VII.57 K. = 218,7-9 Gundert).

Our caution as to the exhaustiveness or finality of the above scheme-and, relatedly, as to whether Galen ever gives us such a final or exhaustive schemeis fuelled by three considerations.

(1) Some-arguably the most important-things categorized under the other psychic subdivisions, perceptual and motor, have a pathology that crucially involves the hegemonic - a point, indeed, emphasized by Galen himself. So, for example, two complaints discussed before we reach the 
hegemonic area, agrypnia and kōma, arise in that part which is common to all the senses, the koinon aisthêtikon (3, VII.58 K. = 222,1-2 Gundert); and both epilēpsia and apoplexia, dealt with in the discussion of impairments of motor function, simultaneously involve impairment of the hegemonic activities (3, VII.58-59 K. $=222,8-12$ Gundert). This adds to our difficulty in identifying a specific category of mental, or even neurological—or even hegemonic: as is clear from both this text and others, apoplexxia, epilêpsia and spasmos involve the whole body, but crucially affect the hegemonic faculty; yet they do not appear under that heading."

(2) The clear distinction into three types of hegemonic activities, including memory, ${ }^{12}$ is not followed up when it comes to the actual listing or discussion of impairments (there are no explicit categories under mnèmoneutikon corresponding to those in the other columns, only the brief remark about loss of memory as exemplified in Thucydides' account of the Plague, VII.62 K. = 226,17-22 Gundert): again, one is led to doubt how fully Galen's theoretical schema corresponds to his actual discussions.

(3) Perhaps most striking: the scheme-and indeed the actual disease entities mentioned-differ between this text and the other most relevant ones. It is true that essentially the same distinction between two kinds of paraphrosyne - one affecting the interpretation of perceptions but not rationality, the other the converse-appears also in Loc. Aff., with some overlap in the 'case histories' cited; on the other hand, the division of paraphrosyne into mania and phrenitis, a central coupling in Caus. Symp., reflected also throughout the corpus, is absent here. ${ }^{13}$

11 A very helpful analysis of the Galenic discussion of eplitêpsia (with listing of all its instances in the Galenic corpus) is in Centanni, M. (1987) 'Nomi del male: "phrenitis" e "epilepsia" nel Corpus Galenicum', Museum Patavinum 5.1, 47-79.

The distinction is repeated in similar form elsewhere in the corpus, as discussed by Jouanna, 'Medical Programme', and by Ricardo Julião in the present volume.

13 The situation is not entirely straightforward. In the present text, at Symp. Diff. 3 (vir.6o-61 $\mathrm{K} .=224,16-226,17$ Gundert), it is two kinds of paraphrosyne e that are manifested by the case histories - that of a person who is otherwise lucid and rational but has the hallucination of pipe-players being present in the room (impairment of phantastikon), and that of a person who perceives the objects about him accurately but behaves irrationally, throwing many of them out of the window (impairment of dianoētikon). At Loc. Aff. 4.2 (VIII.225$27 \mathrm{~K}$.) a variant version of the latter story is contrasted with experiences-including Galen's own-of hallucination, to exemplify the existence of two kinds of phrenitis, one 
Indeed, mania and phrenitis simply do not appear in De symptomatum differentiis $;{ }^{14}$ and, perhaps most striking of all, there is no mention at all of melancholia.

To turn to a brief summary of the crucial discussion of De symptomatum causis (especially 2.7, VII.200-4): again, this is organized according to a distinction between physikos and psychikos, and within psychikos between hegemonic and perceptual and motor: indeed, the treatise explicitly claims to follow the pattern and order of the previous one. Again, we have the problemexplicitly acknowledged — of the overlap between categories; and so again we get a discussion of complaints that involve voluntary activities-the domain of the hègemonikon, see Caus. Symp. 2.2 (VII.149 K.) — before we arrive at the direct treatment of the 'hegemonic'. And again, we are faced with Galen's confusingly plural creation of schemata: yet another tripartite division of symptōmata (loss of activity; damage to activity; distortion of activity) may be broadly equivalent to that in the table above; but in any case, it is largely forgotten in the actual discussion that follows; so too is any notion that there are separate symptōmata of three different domains within the hēgemonikon. There is no mention of conditions that affect phantasia but not dianoia, or vice versa; and no need to consider memory as a separate category: indeed, impairments of rational function (logismos) are coupled with those of memory $(m n \bar{e} m \bar{e})$ at 2.7, VII.200-2, where they are discussed together under the joint heading of 'loss of intelligence or forgetting' ( $\left.\mu \omega \dot{\omega} \omega \sigma \sigma \nu \hat{\eta} \lambda \eta^{\prime} \theta \eta \nu\right)$ : both are caused by cold. It is the passage immediately following on from that discussion, too, that gives us the important distinction, already mentioned, between two types of paraphrosyne $\bar{e}$, characterized by the presence or absence of fever: phrenitis and mania respectively (ibid., VII.202 K.).

The main point one takes, in fact, from this discussion of impairment of brain function, is the clear relationship between the different modes of impairment and conditions of heat and cold, and relatedly types of humour. To summarize: loss of intellective function and memory (mōrōsis and lèthēe are caused by cold; relatedly, apoplexxia and epilēpsia are caused by phlegmatic humour; varieties of derangement or delirium (paraphrosynē, paranoia) always arise from a poor humoral state; within these, only melancholia arises from a

affecting reason, one the perceptions (aisthēseis). See also the discussion of these passages by Julien Devinant and Ricardo Julião in this volume.

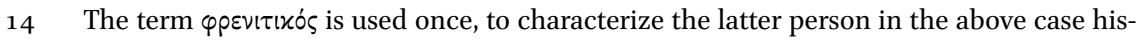
tories (the one with the impaired dianoetikon), but there is no discussion of the concept

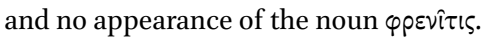


cold one, while mania and phrenitis are associated with a hot one, the latter more specifically with the presence of fever. ${ }^{15}$

Affected Places contains the most substantial discussion relevant to impairments of the brain. Again, it is far from easy to summarize. A particular concern both with the location of bodily affections, and with their conceptualization in terms of 'primary affection' and 'sympathetic affection', leads to a different focus from that of the other two texts which we have just considered; there is, in particular, a long discussion of varieties of melancholic affection in relation to this distinction and to different specific aetiologies. Meanwhile, the understanding of various impairments of the brain in relation to hot and cold, and to related humoral conditions, which we have already observed, is reasserted in detail. So, melancholia is a disease of coldness and wetness; mania is hot and associated with bile; and the aetiology of derangement or hallucination, though not expressible quite as simply as that, consists in some action of precisely the same qualities and humours in the body. ${ }^{16}$ And - a point to which we shall return in our discussion of Galen's practical approaches to treatment - this incorporation of the medical psychic impairments within the physical scheme of qualities and humours is amply reflected elsewhere in the corpus, especially in the Hippocratic commentaries and the pharmacological writings.

Let the above suffice, then, both to give an overview of Galen's classification of the medical psychic impairments and also to give some idea of the difficulties inherent in any such brief summarization; and let us then return to our broad distinction, between the ethical-philosophical model and the medical one.

We might, then, characterize this distinction further by saying that while the ethical-philosophical model is centrally concerned with the interaction between parts of a tripartite soul, and the necessity, for mental or spiritual health, of their correct internal relationship (as explored particularly in Affections of the Soul and in Character Traits), the medical model is concerned almost entirely with the brain and its health or affection, and proceeds essentially as if what is in Platonic terms one part of the soul may be regarded as the whole soul - that is to say on the basis of a single unified soul, situated in the brain. And we might add that while the ethical-philosophical model has

15 See Nutton, V. 'Galenic Madness', in Harris, W. V. (2013) Mental Disorders in the Classical World. Columbia Studies in the Classical Tradition 38, 119-27, for a discussion of mania in relation to the distinction made in this text and elsewhere in Galen.

16 The central passage of text relevant to these issues is Loc. Aff. 3.6-12 (VIII.160-204 K.), with the specific discussion of melancholy at 3.9-10 (VIII.176-93 K.). 
almost nothing to say about bodily correlates or bodily influences upon the three parts of the soul, it is crucial to the medical model that the factors determining mental health and illness are understood as ultimately dependent on the same physical system - the interaction of hot, cold, wet and dry-as underlies everything else in the biological world.

But it is not quite as simple as that. For while the above sketch undoubtedly captures an important distinction-as well as something of the tension, and something of the complexity, that arise from Galen's different writings in this area-the two discourses are not as neatly separate as it suggests. First of all, there are at least a few terms from the ethical discourse which do turn up in the medical one too: they have specific physical correlates or possible physical consequences. One of these is lypēe, distress: a central term in Galen's ethical discourse, and discussed at length, in Affections of the Soul, without reference to any physical correlates, it is nevertheless also understood (and this is mentioned not just in medical texts but also in a passage in Freedom from Distress ${ }^{17}$ ) as leading to sleeplessness and as related to 'dry, hot' physical consequences, which can include fever and in the worst case death. But similar things can be said for anger, shame, fear, joy-a range of emotions or pathe psychess, in fact, which are understood by Galen as intimately related to the actions of the heart, the internal heat and the breath. In fact, there is a fairly rich discourse, especially in works on the healthy daily regime, but also in works which consider disease aetiology and diagnosis, concerning the complex relations between physical and mental factors in relation to this, the middle part (the thymoeides) of the Platonic tripartite soul. ${ }^{18}$ In characterizing the rational soul as a particular mixture within the brain, or as closely dependent on such a mixture, as he does in The Soul's Dependence on the Body, Galen is, then, one might think, not necessarily considering that rational soul in isolation from its relationship with the non-rational soul. Anger is associated with heat, fear with

17 Ind. 3 (4,6-11 BJP). On lypē see also Mattern, S. M. 'Galen's Anxious Patients: Lypē as Anxiety Disorder', in Petridou, G. and Thumiger, C. (2016) Homo Patiens-Approaches to the Patient in the Ancient World, 203-23 (who however seems to me somewhat to overuniversalize a particular medical understanding of lype throughout the corpus) and Singer, P. N. 'A New Distress: Galen's Ethics in Peri Alypias and Beyond', in Petit, C. (forthcoming) A Tale of Resilience: Galen's Пгpi à $\lambda v \pi i \alpha \varsigma$ (De indolentia) in Context. Texts exploring this relationship-the physical correlates of these emotional disturbances - are discussed in depth by Singer, 'Rage'; note that (amongst many other relevant passages throughout the corpus), the fullest account of such physical relations of the pathe psychēs is that at Caus. Symp. 2.5 (vII.191-4 K.) - that is, in the immediate leadup to the discussion in that text of the medical psychic impairments, considered above. 
coldness; yellow bile has a close relationship with anger and distress. Thus, the effect of such external physical factors as heat and cold on the brain could also, arguably, at least in some contexts, be considered as the internal effect of a non-rational part on the rational. By the same token, the heart and the liver are, in Galenic theory, the seats of psychological drives as well as of physical functions-drives which must, at least theoretically, be taken to interact, and potentially to conflict, with those of the brain, in a way which provides a physical correlate for the tripartite soul interaction which we saw, above, in the ethical (non-physical) works. I say 'at least theoretically': such interaction seems to be hinted at, rather than clearly described, in the case of the heart, while in that of the liver there seems very little, if any, account of how the desiderative drives find an observable physical counterpart. Still, it remains the case that, even in the medical discourse, the brain is not the only relevant seat of the psychological; and that some kind of internal soul interaction is conceived of in physical terms, however imperfectly these terms appear.

So much, then, by way of summary of the theoretical problem, a summary which I hope does justice to the extent to which distinct medical and ethical discourses and traditions, with distinct concerns and vocabulary, are in operation in the Galenic texts, but also to the limitations to that distinctness-as well as to the complexity of the interpretive situation.

\section{Galen's Philosophical and Medical Cures for the Pathological Soul}

I turn to consider the range of actual approaches to treatment of the soul's pathe that Galen suggests. It seems to me that one may-without prejudging or attempting to answer the above question on the extent to which different 'models' are reconciled-identify four main types of intervention.

I list the four here, before proceeding to give more detail as to what is entailed in each, and exemplification by texts. (Note that in this list the term "cognitive therapy" is not used with any intention of suggesting a direct equivalence between ancient and modern 'psychotherapeutic techniques', but rather as a shorthand to indicate a range of philosophical or dialogic interventions, which are sometimes referred to under the heading "therapy of the word" and which will be discussed in more detail in what follows.)

1. Cognitive therapy for ethical/emotional disturbances (the pathē psychēs of the ethical tradition): distress, rage, lust, greed, etc.

2. Cognitive therapy for the medical psychic impairments (esp. delusions, which may or may not be connected with melancholia) 
3. Medical therapy for the medical psychic impairments (e.g. epilèpsia, kōma, phrenitis, melancholia)

4. Regimen: early and ongoing physical and intellectual training and habit-development.

\section{Cognitive Therapy for Ethical/Emotional Disturbances}

This approach is most fully exemplified in the short ethical works, Affections and Errors of the Soul and Freedom from Distress. Here, there is a serious attempt to use 'therapy of the word', rational engagement, to influence behaviour, without consideration of physical causes. (Of course, it should be noted that the kind of pathos psychēs addressed here may, if prevention or treatment is unsuccessful, have serious medical consequences - and indeed such an eventuality is mentioned in Freedom from Distress, in a passage already touched upon; see n. 17 above. At that point, then, we would be considering a medical problem which is outside the realm of the pathos psychēs itself, and as such is not addressed in these texts.)

I identify five specific techniques as being particularly highlighted in these two texts:

(a) the use of an impartial monitor of one's ethical shortcomings

(b) direct 'therapy of the word'

(c) daily anticipation and/or retrospective assessment of progress or ethical challenges

(d) consideration of the worst one may suffer

(e) contemplation or 'visualization' of aesthetically attractive and unattractive personal ethical consequences.

Technique (a) is discussed and elaborated in chapter 3 of Affections of the Soul (Aff. Pecc. Dig. 1.3, v.7-14 K. = 7-11 de Boer). The essential requirement is that of finding an impartial person, of good judgement, who is prepared to take on the task of pointing out to one each of one's ethical shortcomings, on a daily basis.

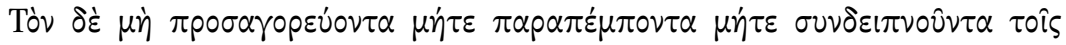

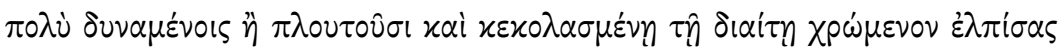

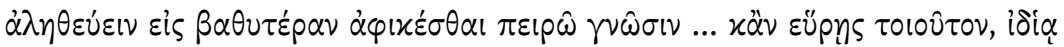

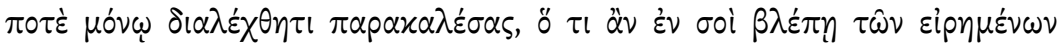

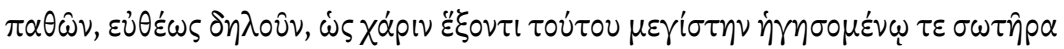

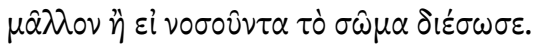


If you find a man who does not greet, attend upon, or dine with men of power and wealth, a man who follows a disciplined daily regime, you may hope that he will speak the truth. But you must attempt to achieve a deeper knowledge of his qualities ... If you find that he is that kind of person, take some opportunity to talk to him in priavte. Ask him to make evident to you directly which of the above-mentioned affections he sees in you, emphasizing the gratitude you will feel towards him: he will be your saviour, even more so than the man who saves you when you have a bodily sickness.

AFF. PECC. DIG. 1.3 (V.9 K. = 7,21-8,4 de Boer)

Technique (b), direct verbal intervention, the 'therapy of the word', seems to be shown by what Galen recounts, in chapter 4 of Affections of the Soul, of the episode of his irascible Cretan friend who seriously injures two of his own slaves when he loses his temper.

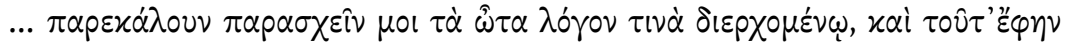

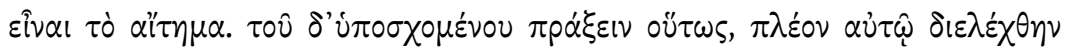

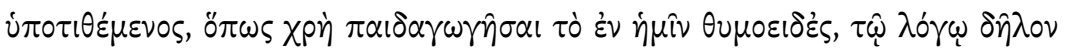

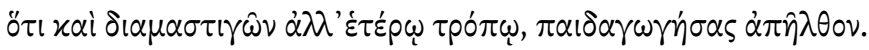

... I commanded him to submit his ears to an argument that I would expound ... He promised to do so, and I discoursed at some length, explaining what sort of schooling is appropriate for the spirit of rage in us - that of the word, of course; I gave him his flogging — but of a different kind! And with this schooling I left him.

AFF. PECC. DIG. 1.4 (V.20 K. = 15,1-5 de Boer)

It is noteworthy, however, that while giving this example of an occasion when such verbal intervention was appropriate-and was carried out—Galen gives us nothing of the words actually used. He is simply asserting the importance of such 'schooling of the word', ${ }^{19}$ without giving details of its content. The words

19 In detail, what he says to the Cretan friend is not unproblematic nor without textual difficulties. In fact, on my preferred reading, given here, Galen seems to do little more, even while talking to his friend, than assert the importance of 'verbal schooling', rather than actually to give it — though the metaphorical phrase "flogging—but of a different kind" seems to imply something more emotionally vigorous. (A very subtly different reading, preferred by de Boer, would take $\hat{\omega}$ (instead of $\tau \hat{\omega}) \lambda \sigma^{\prime} \gamma \omega$ with $\pi \alpha \iota \delta \gamma \omega \gamma \eta \dot{\gamma} \sigma \varsigma$ — "with which 
used by the monitor in technique (a) may-again Galen gives no actual examples of them, but the nature of their envisaged content is clear enough — be the clearest actual case of the therapy of the word in action.

On the other hand, it is worth pointing out that the words of this treatise themselves - the speech which was supposedly held in public on the topic of how to cure one's affections and errors-are themselves part of the therapeutic process. The participation in such a discourse, whereby one listens to a theoretical and partly anecdotal account of how one may discern one's faults and become better, is clearly envisaged as part of the reader's or listener's own process of self-improvement. Relevant here is the range of genres which is, in some sense, theorized and exemplified by Galen himself. The genre which will persuade people to take the ethical project seriously in the first place is that known as protreptic; Aff. Pecc. Dig., meanwhile, belongs to a different genre, logically subsequent to that, offering practical techniques of self-analysis and self-improvement to those who have decided to embark upon that project. ${ }^{20}$

Techniques (c) and (d) potentially also in involve the use of texts or treatises, though in a different way.

Technique (c) — the daily assessment of progress—is described in chapter 6 of Aff. Pecc. Dig. 1, and also in less detail in Ind.

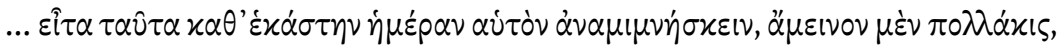

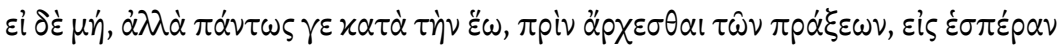

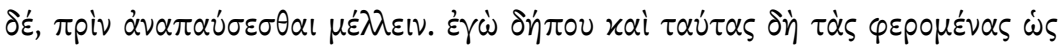

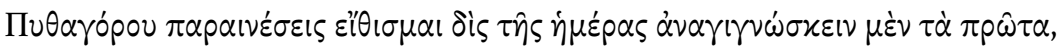

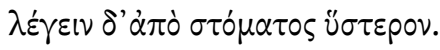

speech, of course, and with a flogging, but of a different kind, I schooled and left him" - so that perhaps on that reading Galen is claiming to have administered more in the way of an on-the-spot paidagōgia. See Singer, Psychological Writings, 255.) Quite how one administers such on-the-spot verbal schooling is not clear: the subject is already remorseful, and perhaps persuasion of the need for ongoing verbal therapy and use of a monitor is indeed the essential.

20 See Aff. Pecc. Dig. 1.1 (V.2 K. = 3,13-17 de Boer); ibid. 1.6 (v.34 K. = 23,14-16 de Boer), with Singer, Psychological Writings, 206-7, 238 n. 7, 240 n. 13 and 267 n. 173; a tripartite distinction of ethical genres - protreptic, therapy and advice-was attributed to Philo of Larissa, and it is possible that Galen draws on this tradition. Galen has not left us a 'protreptic' on ethics, but his Protrepticus to the study of the arts, or of the art of medicine, has a similarly broad apparent audience and moralistic enthusiasm in its attempt to 'convert' people to a cause. 
... one should remind oneself of these things, preferably many times a day, or, failing that, at least at dawn before the beginning of one's daily activities and in the evening when one is about to take one's rest. I myself have developed the habit, first of all to read the Precepts attributed to Pythagoras twice a day, and in more recent times to recite them from memory.

AFF. PECC. DIG. 1.6 (V.30 K. = 21,5-10 de Boer)

This is interestingly dietetic in its nature, reminding one of descriptions Galen gives elsewhere, in San. Tu., of appropriate daily regimes for particular conditions: these typically involve instructions as to what one does at dawn, and then at later times of day, and the timing of these in relation to one's rest. Here the 'dietetic' practice recommended is a daily, and preferably repeated, selfreminder; more specifically, Galen mentions his own habit of the repeated daily reading or recitation of phrases from the Pythagorean Precepts (also known as the Carmen Aureum).

It is not certain that the 'Pythagorean' text mentioned here by Galen is the same as the corresponding text which has come down to us, though the identification seems plausible, and indeed Galen seems at times to echo that text verbally; ${ }^{21}$ in any case the daily practice of self-interrogation recommended in that text ${ }^{22}$ surely represents accurately the content of the lines which Galen suggests we should be repeating to ourselves.

Technique (d) - the praemeditatio malorum - though an acknowledged technique, known from other ancient self-improvement texts, is not clearly present in Affections. It is, however, described fully in Ind. Here, too, the knowledge or recitation of a text is of assistance in the performance of mental practice; this time the text is one from that most popular source, in this period, of morally exploitable quotations: Euripides. ${ }^{23}$

21 On this question see Singer, Psychological Writings, 264 n. 157. As we see below, Galen quotes a line identical to 1.12 of the extant Carmen at Aff. Pecc. Dig. 1.5 (V.26 K. = 18,25 de Boer).

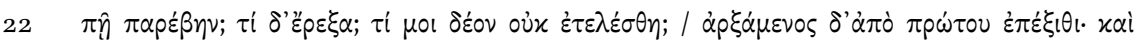

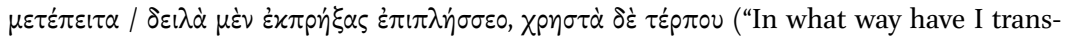
gressed? What have I done? What have I not achieved that I should have? / Start from that beginning and then continue; and then / Rebuke yourself for your vile deeds, and take joy in the good ones"), Carmen Aureum 42-44, recommended for recitation also by Epictetus: Diss. 3.10.3.

23 Rather bizarrely, in relation to the structure of this very short treatise, the relevant lines appear twice. While one is tempted to suspect the text, or to accuse it of infelicity, this 


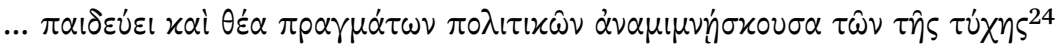

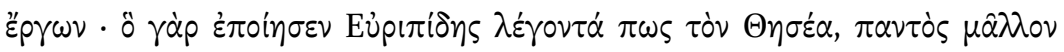

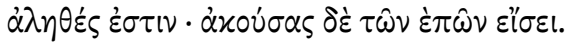

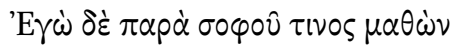

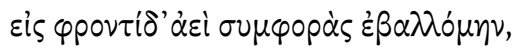

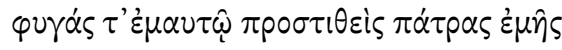

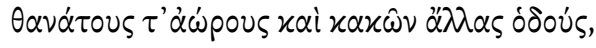

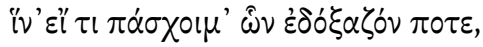

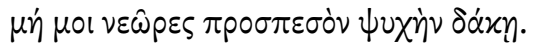

... observation of politics is a good teacher by reminding us of the actions of chance. What Euripides put into the mouth of Theseus is true above all, as you will recognize when you hear:

As I once learned from a wise man,

I fell to considering disasters constantly,

Adding for myself exile from my native land,

Untimely deaths and other ways of misfortune,

So that, should I ever suffer any of what I was imagining,

It might not gnaw at my soul because it was a novel arrival.

IND. $52-3(16,21-17,9$ BJP, trans. Nutton)

Technique (e) is highlighted in chapters 5, 6 and 9 of Affections. The key point here is the negative and positive emotional responses that can be produced by the sight, or visualization, of, respectively, fine and shameful behaviour.

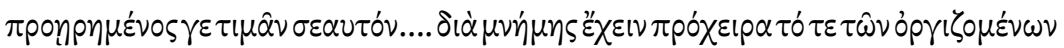

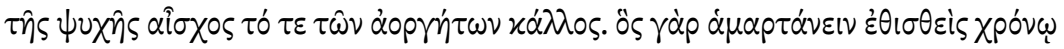

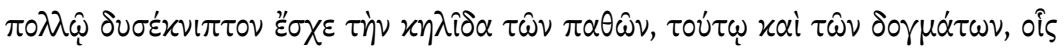

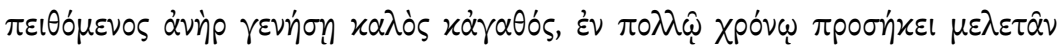

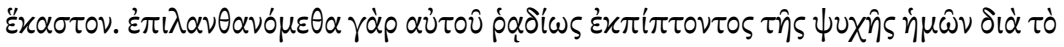

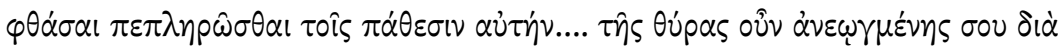

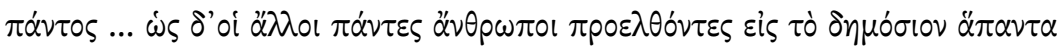

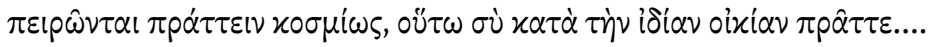

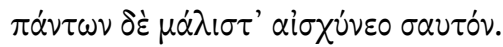

feature is perhaps rather something which serves to bring home this very point of the value of textual repetition.

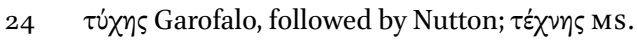


... if you really have made this choice in favour of self-esteem ... have to hand in your memory the ugliness of soul of those who get angry, by contrast with the beauty of those who are free from anger. For someone who through a long period in which he has developed the habit of error has acquired a stain of affections so deep that it is hard to wash out ought to spend a long time too in the practice of obedience to the doctrines by obedience to which you may become a decent man. For we forget such doctrines, which are easily removed from our souls, because our souls have already become filled with affections.... Have your door open ... constantly ... in the same way that people in general attempt to make all their actions fine ones whey they enter a public arena, you do the same in your own home ...

'First and foremost of all men, have shame for your own self.' AFF. PECC. DIG. 1.5 (V.25-6 K. $=18,3-25$ de Boer)

As well as asserting the central role of a sense of shame with regard to one's own actions, this passage is also interesting for the relationship between the rational (and error) and non-rational (and pathos), which turns out to be somewhat more complex than the initial distinction suggested. It seems here that failure to keep in one's (rational) mind the correct doctrines in effect brings about a vacuum, which the pathe rush to fill. We note also that the passage's concluding flourish is another textual quotation of the sort that Galen has recommended; in fact, it is from the Pythagorean Carmen Aureum (12, 94-5 Thom). The emotive reaction to fineness/ugliness of action is explored further:

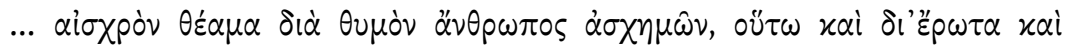

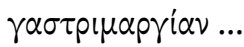

... a human being disfigured by rage is an ugly sight, so too is one disfigured by lust or greed ...

AFF. PECC. DIG. 1.6 (V.27 K. = 19,15-17 de Boer)

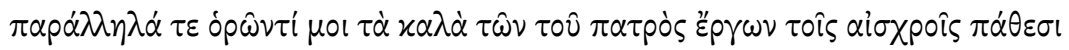

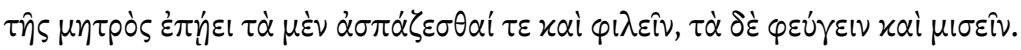

Thus, as I saw alongside each other the fine qualities of my father's deeds and the ugly affections to which my mother was subject, I was moved to warmth and love for the former, and avoidance and hatred of the latter.

AFF. PECC. DIG. 1.8 (V.41 K. $=28,2-4$ de Boer) 


\section{Cognitive Therapy for Medical Psychic Impairments: Commentary on Hippocrates' Epidemics}

The material is sparse, but Galen recounts cases-albeit somewhat bizarre ones - where the doctor pretends to accept the patient's delusion as reality, in order then to persuade him or her out of it.

Such instances occur in the Commentary on Hippocrates' 'Epidemics II', a text which survives only in Arabic translation. Galen recounts the case of a doctor's response to a woman who believes herself to have swallowed a snake. He gives her an emetic, and conceals a snake in the vessel into which she then vomits; she is thus freed of her delusion. Even more elaborately, a doctor assists a patient who has had the delusion (leading to sleeplessness and fever) of a dead man calling to him from a graveyard, by feigning anger with the man, claiming that it was he himself who was called to the man, to ask for his help against robbers. ${ }^{25}$

A number of things are worth noting about these accounts. One is that these are not Galen's own 'case histories': at the end of the account they are attributed to the doctors Chrysippus and Erasistratus respectively. ${ }^{26}$ Another is that in such contexts, in his commentaries on the Epidemics, Galen is more interested in diagnostic techniques, including those enabling one to distinguish physical from psychogenic pain, or to identify falsehood and malingering, ${ }^{27}$ than in therapy. The same is even truer of the well-known 'case histories' involving psychogenic illness and erotically-motivated depression in Prognosis. In this case, indeed, I have not quoted the relevant passages for consideration, as they in fact contain no actual recommendations for therapeutic intervention: Galen's discovery of the true cause in these cases is the medical success which the text celebrates. We find out, for example, that the cause of a married lady's sleeplessness and melancholy-like symptoms is her infatuation with

25 Hipp. Epid. II 2 (207,45-208,17 Pfaff).

26 A similar 'case history' which Galen apparently borrowed from the previous traditionalthough he presents it as his own experience and, as indeed Susan Mattern argues in a forthcoming paper, such anxiety may have been a recurrent one-is that of the person who fears that Atlas will cease to hold up the heavens, this being the cause of a melancholy condition, Hipp. Epid. I 3.1 (XVIIA.213-14 K. = 107,26-30 Wenkebach). (Both this and the two 'case histories' with which we started this section are mentioned again at Hipp. Epid. VI 8, 487,3-16 Pfaff; at this latter mention there is no discussion of the attempted 'cure'. See also Julien Devinant's discussion of these passages, above, 209-14.)

27 On this see esp. Hipp. Epid. II 2 (206,8-207,40 Pfaff). Further on malingering, see Julien Devinant in this volume, 212-13. 
the dancer Pylades; ${ }^{28}$ what we do about that, however, is entirely outside the discussion. This very feature of the text, however, is something on which it is worthwhile to reflect.

\section{Medical Therapy for Medical Psychic Impairments}

Examples of Galen's clinical practice in such cases are found especially in Affected Places and The Therapeutic Method. The number of passages, however, in these major works which directly describe the therapy of such mental impairments is, however, small (although, as we shall see below, it is to some extent supplemented by more general remarks on the therapeutic procedures, as well as by accounts of the use of certain drugs in the pharmacological works).

As we shall discuss further below, there is much more attention on the distinction, and on the importance of one's distinguishing, between different types of brain-affection (e.g. the three types of melancholy and three types of epileptic affection, Loc. Aff. 3.11, VIII.193 K.), or on the exposition of general principles (see above on De symptomatum causis and De symptomatum differentiis) than on the prescription of treatment. And, although there is certainly some material giving evidence of specific physical medical interventions, the account of these in relation to the complex medical categories which Galen has identified is very far from systematic.

\section{Some Treatments for Melancholy}

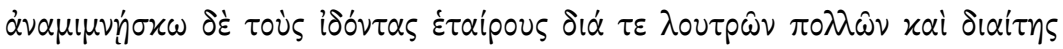

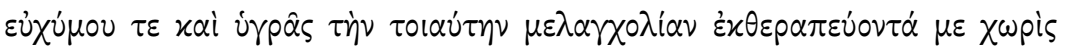

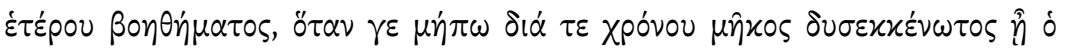

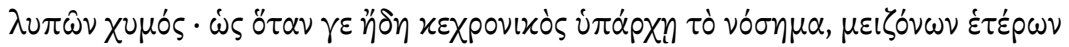

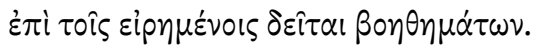

I remind those followers who have seen me treat this kind of melancholy through a well-humoured, wet daily regime, without any other remedy, whenever the humour causing the distress is not yet difficult to dislodge because of the length of time; when, on the other hand, the disease is already well-established, it requires other, stronger remedies.

LOC. AFF. 3.10, VIII.192-93 K.

28 Praen. 6 (XIV.631-36 K. = 100,15-102,27 Nutton). That case is followed by another involving a concealed psychogenic cause, that of a steward whose anxiety is due to an accounting irregularity (ibid., XIV.633-34 K. = 102,29-104,8 Nutton); for discussion of this material see now Singer, 'Rage'. 
Some Treatments Applied to the Head in both Excited and Lethargic Diseases

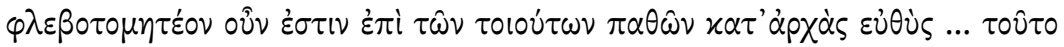

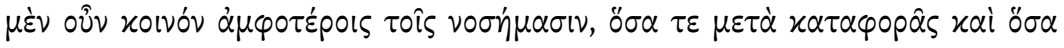

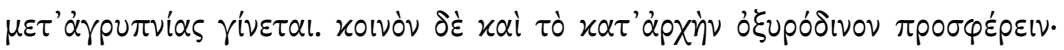

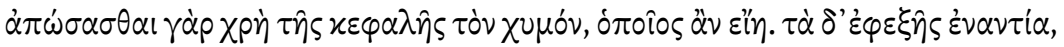

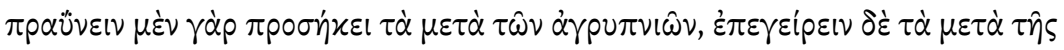

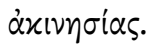

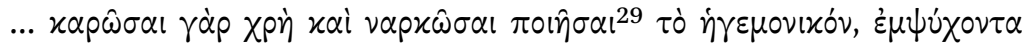

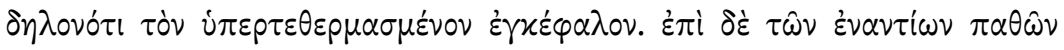

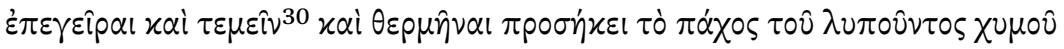
...

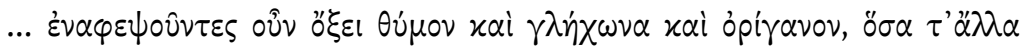

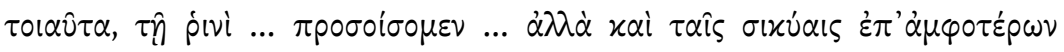

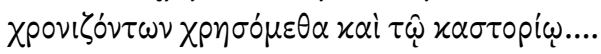

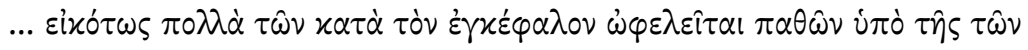

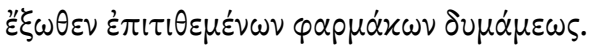

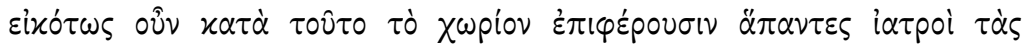
$\dot{\varepsilon} \pi \mathrm{\beta} \rho \circ \chi \dot{\alpha} \varsigma \tau \hat{\eta} x \varepsilon \varphi \alpha \lambda \hat{\eta} \ldots$

You must carry out phlebotomy right at the outset in such affections [sc., diseases involving both lethargic and over-excited mental states] ... This ... is common to both diseases; [that is], both those that occur with lethargy and those that occur with wakefulness. Common also ... is the application of oxyrrhodinum, for it is necessary to repel the humour from the head, whatever sort it might be. But what come next are opposites, for it is appropriate to calm in the diseases with wakefulness and to rouse in the diseases with inertia....

... it is necessary to make the hègemonikon sleepy and numb, cooling, obviously, the overly heated brain. However, in the opposite affections, it is appropriate to rouse and to cut and heat the thickness of the distressing humour ...

... We shall apply Cretan thyme boiled down in vinegar, pennyroyal, oregano and other such things to the nose ... But also, in both cases, if they are chronic, we shall use the cupping glass and castor.... There is, reasonably enough, a benefit for many of the affections of the brain

29 Sic Kühn and Loeb; presumably one should read $\nu \alpha p x \hat{\omega} \delta \varepsilon \varsigma \pi \circ \imath \hat{\eta} \sigma \alpha l$ (or omit $\pi \circ \imath \hat{\eta} \sigma \alpha l)$.

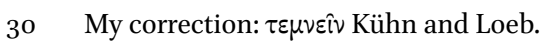


through the potency of externally applied medications.... It is, therefore, reasonable for all doctors to apply irrigations to the head to this part (i.e. the coronal suture) in particular ... ${ }^{31}$

A number of points are worth making here. First, it is noteworthy that this is not a dedicated discussion of mental or neurological disturbances. There is, in fact, no such dedicated discussion in Galen's therapeutic magnum opus; nor, indeed, is there any single work dedicated to this category of medical psychic impairments. Rather, this passage comes in the context of a discussion of the importance of considering the 'affected place' in each case, and also of a polemic against Thessalus and others for thinking of the leading-part (hêgemonikon) of the soul as being in the heart.

This leads us to a further consideration, namely the extent to which the disease items identified here are conceived as manifestations, or symptoms, of physical conditions or syndromes. In fact, while we have isolated certain terms as corresponding to mental disease entities for the purposes of this studyand while mania, melancholia and phrenitis, for example, do of course involve disturbances or aberrations of the reasoning-faculty in the relevant sensethey are largely conceptualized as corresponding to imbalances within the humoral or four-qualities system of the body, and/or as related to the system of fevers. They seem, in many contexts, to lack the independent status of 'disease entities', being considered rather as belonging within broader syndromes; and they are often of more interest for specific physical consequences than for mental ones.

The concept melancholia provides a particularly good example of this; and the short text Black Bile (At. Bil.) functions as a good summary of this example. Here-with the exception of one mention of "falling prey to melancholy" and one mythological reference, brought forward in the context of a polemic against Erasistratus, to the daughters of Proetus, whose "melancholic madness" was well known (at least in Galen's interpretation of the myth) to have been cured by the purgative hellebore-the focus is entirely on black bile (referred to either as melainē cholē or as melancholikos chumos) in its physical nature and causation: on how it is produced, and eliminated, in the body, on its relationship with the natural constitution of the animal and with environmental factors, and on its physical medical consequences. These include elephas, karkinos and the fatal nature of cases where the substance is voided in its pure form, as observed for example in cases of Plague. These physical complaints

$31 \quad M M 13.21-22(\mathrm{x} .930-34$ K. = iii.402,9-408,11 Johnston and Horsley); trans. Johnston and Horsley, slightly adapted. 
take a more prominent position, amongst a range of 'melancholic' complaints broadly conceived, than does melancholia itself-which indeed appears as a noun only three times in the text. ${ }^{32}$

There is, to be sure, a mental, experiential aspect to melancholia; but it is perhaps significant that Galen, at most mentions of the term, seems as it were to take this as read, without describing or elaborating on it. There are exceptions to this: a number of texts take the well-known Hippocratic Aphorism-

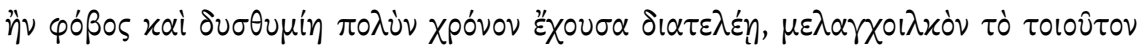
("if fear and low spirits continue for a long time, such a thing is melancholic") - as their starting-point and elaborate this experiential account of melancholia. (The 'case histories' from Prognosis and the Epidemics commentaries mentioned under 2. above are also understood as melancholic, or as similar to melancholia in their presentation.) The condition is characterized by fear and despondency, and could be taken, with all appropriate cautions, as a rough equivalent to what we understand under the term depression. Further psychological details are given: patients fear death, but sometimes also long for it; and the condition may also involve certain specific anxieties or delusions. ${ }^{33}$

32 Falling prey to melancholy ( $\left.\mu \varepsilon \lambda \alpha \gamma \chi \chi \lambda \hat{\alpha}_{\alpha} \dot{\alpha} \lambda \hat{\omega} v \alpha \mathrm{l}\right)$ : At. Bil. 4 (V.118 K. $=78,16-17$ de Boer); the melancholically-based mania of Proetus's daughters: ibid. 7 (V.132-33 K. = 85,26-86,5 de Boer); physical nature, production in body and effects: e.g. ibid. 3 (v.110-13 K. = 74,16-75,21 de Boer); observations on voiding and on relationship to diet, environment and physical consequences: e.g. ibid. 4 (V.114-18 K. $=76,15-78,6$ de Boer); physiology in relation to the spleen, and the effects of specific purgatives: e.g. ibid. 6 (v.126-28 K. $=83,1-84,2$ de Boer). The three occurrences of the noun are in the first two passages cited above, and in an introductory reference to Rufus of Ephesus' writings on the subject, ibid. 1 (V.105 $\mathrm{K} .=71,12-14$ de Boer). On the scarcity of melancholia as a noun as opposed to adjective in Galen, cf. the discussion above, 20, n. 38, with reference to the parallel case (predominance of verb over noun forms) in the Hippocratic Corpus, and the discussion by Chiara Thumiger mentioned there.

33 The text is Aph. 6.23. At Caus. Symp. 2.7 (VII.203-4 K.), citing this text, Galen proceeds to describe the twin presentations of fear of death and, in some cases, longing for death, and to relate this fear to the darkness of the humour itself; at Loc. Aff. 3.10, VIII.188 K., he cites the same text, going on (viII.190-91 K.) to mention not only fear, but particular delusions (believing oneself to be breakable) or anxieties (Atlas may tire and drop the cosmos), as well as hostility and sullenness, again relating the emotional disturbances to the physical nature of the substance. Cf. also the discussion of the Hippocratic text ad loc. in Galen's actual commentary on the Aphorisms. There, at Hipp. Aph. 6.23 (XviIIA.35 K.), Galen focusses on the lack of an apparent cause for fear or low spirits (on which point cf. Loc. Aff. 6.5 , VIII.418 K.) - or their unusual prolongation, even if they initially did have an apparent cause - as a key criterion in the diagnosis melancholy. Again, though, the extreme brevity of his comment on the text is perhaps significant for the status of melancholia as a disease entity in Galen. 
In most passages where the term or its cognates appear, however, there is no such interest in the experiential particularities or psychological manifestations (let alone-with the few anecdotal exceptions we considered under 2. above - of a distinct psychotherapeutic approach to them). The overwhelming preponderance of mentions of the term is in the context of its analysis within the scheme of the humours and qualities, and, more precisely, in the specification of the standard treatments to re-establish humoral balance: blood-letting and/or evacuation through the bowel. ${ }^{34}$ The appropriate treatments thus address excess melancholic humour as a physical problem, one with (largely) both physical aetiology and physical conseqences, and are interventions designed to re-balance the mixture, in just the same way as the interventions appropriate to any other bodily imbalance.

The adjective melancholikos, in the majority of its instances in Galen, functions to identify either particular substances in the body or a category of illnesses related to those; in this, again, it it is a parallel term to phlegmatic, bilious, etc.

A series of examples from the pharmacological writings will exemplify these points. Amongst ill-balanced bodies, Galen writes, vinegar is beneficial to the bitter-bilious, but counter-indicated for the melancholic; ${ }^{35}$ chamomile is beneficial for some, though not all, fevers, including those which are melancholic, phlegmatic or arising from the inflammation of an organ; ${ }^{36}$ hard lumps are all either phlegmatic or melancholic in their substance, or a mixture of both; ${ }^{37}$ there is blood which is truly so, or that which is mixed with a humour, for example the melancholic. ${ }^{38}$

The discussion, still drawing upon the pharmacological writings, may be widened to other medical psychic impairments. In the cases of mania, karos

34 Another striking Galenic reference to melancholy, again from his commentary on the Aphorisms, has the author claiming that one of his patients would come to him every year spontaneously to commence his regular purgative treatment, as soon as he noticed the onset of symptoms: Hipp. Aph. 6.67 (XviIIA.78-79). Here, it is presumably—but again no detail is given - the psychological symptoms which are relevant to this self-diagnosis (and the same phrase for "falling prey to melancholy" is used as noted at n. 32 above: $\mu \varepsilon \lambda \alpha \gamma \chi 0 \lambda i \alpha \dot{\alpha} \lambda \dot{i} \sigma \kappa \varepsilon \tau \alpha \mathrm{l})$; yet it is worth noting that the broader context is a discussion of a range of humoral conditions which require such purgation: these may be phlegmatic or bilious, not just melancholic.

$35 S M T 1.23(\mathrm{XI} .438 \mathrm{~K}$.$) .$

$36 \quad s M T 3.10(\mathrm{XI} .563 \mathrm{~K}$.$) .$

$37 \quad S M T 5.9$ (XI.737 K.).

$38 \quad S M T 10.2$ (XII.253 K.); and cf. ibid. 11.2 (XII.382 K.) on evacuations; Comp. Med. Loc. 6.9 (XII.1003-4 K.) on phlegmatic versus melancholic humour; Comp. Med. Gen. 4.2 (XIII.667$68 \mathrm{~K}$.) on melancholic blood in need of purgation by venesection. 
and lèthargos, for example, the adjectival cognates may be used to refer to substances, including drugs. Black-seeded henbane (iooxviauos), for example, is "manic" and "karotic". ${ }^{39}$ More broadly, we see again the way in which the medical psychic impairments are embedded in the system of qualities, hot, cold, wet and dry. Wet, cold pathē in the brain, for example, attract certain specific remedies, while one should treat phrenitis and all lethargic and kataphoric pathe accompanied by fevers with rodinon to the head and neck; amid many examples of this type of treatment, some texts focus on the actual underlying principle for it, which is that one is trying to cool the body. ${ }^{40}$

Thus, we see that the very small number of Galenic 'case histories' relating to the medical psychic impairments may be supplemented by general remarks on their treatment, especially in the pharmacological works. By the same token, we see that these latter texts serve to re-emphasize the extent to which the illnesses in question are absorbed into the physical, humoralist description of the body and its pathology.

If we find it striking how uninterested Galen is in such mental aberrations as melancholia, phrenitis or mania 'in their own right' - to put it another way, the extent to which they are subsumed within physical syndromes, indeed with the physical manifestations or outcomes being of more interest than the mental ones-that perception is surely reinforced when we turn our attention to that most famous mental disturbance of ancient medicine, the hysterical.

Galen's main discussion of hysterical women, their symptomata and related matters is again in Affected Places (Loc. Aff. 6.5 = VIII.413-37 K.). The term used,

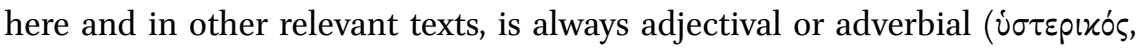

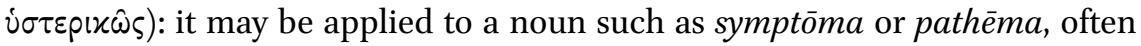
more specifically to apnoia or pnix to denote the 'hysterical suffocation' which is central to the presentation of this illness; sometimes it is applied to the women themselves..$^{41}$ In terms of symptoms, the focus is on this absence of breath and the related syndrome (absence of pulse, loss of consciousness), or on a physical pathology involving spasm-like motions of the womb. In terms of

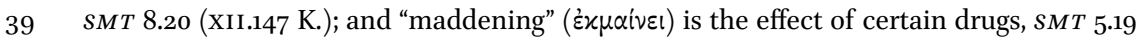
(XI.767 K.).

$40 \quad S M T 11.15$ (XII.341 K.); Comp. Med. Loc. 2.1 (XII.523-24 K.); ibid. 2.3 (XII.597 K.); SMT 3.9 (XI.559 K.).

41 Alongside the discussion in Affected Places, see also Diff. Resp. 3.10 (VII.943 K.), 3.13 (VII.959 K.); Hipp. Prorrh. I 3.26 (XVI.773 K. = 139,20-31 Diels); Comp. Med. Loc. 7.3 (XIII.66 K.), 7.5 (xIII.103 K.), 8.3 (xIII.166 K.), 9.4 (XIII.285 K.), 9.10 (XIII.319 K.); Hipp. Aph. 41 (xvir .540 and 824 K.); Caus. Puls. 4.22 (IX.197 K.); MMG 1.15 (XI.47 K.); De semine 2.1 (IV.598-99 K. = 150,5-11 De Lacy); Hipp. Epid. VI 1.2 (XviIA.805 K. = 9,33-10,5 Wenkebach); SMT 11.28 (XII.348 K.). 
aetiology and treatment, the focus is on the withholding of seed, on resultant physical distortions to the womb, and on the need to expel the seed. While the typical aetiology involves widowhood and an unaccustomed abstinence from sexual activity, the psychological or experiential aspect of this situation-or indeed of the hysterical condition itself-seems wholly absent from Galen's account. One may object that such a remark is based on an anachronistic misunderstanding of what 'hysterical' means in Galen's medical culture- that it is, for him, simply an illness with certain clear physical symptoms and without any psychological or mental component. Yet two things speak against this. One is the phrase "in no way harmed in their reasoning-faculty" ( $\mu \eta \delta \dot{\varepsilon} \nu \beta \varepsilon \beta \lambda \alpha \mu \mu \varepsilon \dot{\varepsilon} \nu \alpha \varsigma$ $\tau \circ \hat{\nu} \lambda$ 위 $\mu \circ \hat{0}$, ibid. VIII.414 K.): this qualification, within Galen's introduction to the variety of forms taken by the illness, surely suggests precisely that harm to the reasoning-faculty was a manifestation that could be expected. But it is not one to which he devotes any attention in the following discussion. The other, appearing earlier in the very same sentence, is the reference to women who identify themselves as hysterical, presumably on the basis of a term in

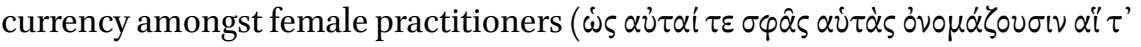
i $\alpha \tau$ i $(v \alpha \mathrm{l} \pi \rho \dot{\sigma} \tau \varepsilon \rho \alpha \mathrm{l})$. Such a widespread current understanding of the term, one would think, surely bespeaks a conceptualization which involves a psychological, experiential dimension to the illness, not one based wholly on physical symptoms. If that is so, it is striking - here even more than in the case of melancholy_how Galen has chosen to discuss it purely in terms of bodily pathology and treatment.

To the above line of argument, the following objection might be made: Galen has no separate category of mental illnesses; it is we who-on the basis of some imperfect, if not actually confused, perception of similarity between certain symptoms or syndromes which he describes and our modern categories of 'mental' and 'neurological' - attempt to impose it upon him. ${ }^{42}$ Why should we be disappointed or puzzled if we then fail to find it?

Yet this objection fails in one important respect: Galen does have a separate category of the soul, and ways of categorizing both its activities and its pathology. As we have seen above, he in some contexts (the ethical) addresses this pathology in its own right, and in the medical context too has a terminology and distinctions which individuate distinct categories of psychic and/or hegemonic pathology. Indeed, the dietetic discourse of De sanitate tuenda (on which see the next section) is relevant here too; for while in a sense this tends to absorb mental activity or pathē psychēs into a physicalist dietetic discourse,

42 For fuller discussion of this conceptual problem, see Julien Devinant's chapter in this volume. 
at the same time, conversely, it distinguishes 'of the soul' or 'mental' as a distinct category which has to be taken seriously by that discourse.

\section{Regimen: Early and Ongoing Physical and Intellectual Training and Habit-Development}

This fourth heading is closely related to the first. There are many texts which could be considered, and in the interests of concision I omit further in extenso quotations. But we should consider how, in a range of works, Galen emphasizes the importance for the soul of early education, and of correct ethical habituation. ${ }^{43}$ The training and habituation include diet and daily exercise alongside early intellectual and musical inputs; and in De sanitate tuenda, in particular, Galen presents the healthy development of the body and that of the soul as conceptually distinct but intimately connected, and explores the two-way interaction between them. A healthy soul is medically important because its ill health will negatively affect that of the body; and certain habits and forms of training (involving e.g. music, hunting and combat, active and passive exercise) contribute in different ways to the health, or to the various excellences, of the soul. Here, poetic, theatrical and musical diversions are included in the repertory of therapeutic interventions relevant to the state of the soul. The focus, however - as also in Galen's Ars medica, another text which considers emotional factors in the context of overall lifestyle-is ultimately on the importance of mental or emotional factors for health of the body. ${ }^{44}$

43 The importance of, and specific techniques employed in, ethical self-training are of course the central theme of both Affections and Errors of the Soul and Character Traits (for discussion of which see especially Gill, Naturalistic Psychology and Singer, Psychological Writings). The vital role, in the correct development of the soul, of early education and training, both ethical and logical-mathematical, is emphasized at Ind. 58-6o (18,17-19,13 BJP); Aff. Pecc. Dig. 1.8 (V.40-43 K. = 27,20-29,16 de Boer); Mor. 3 (44,1-17 Kraus = Singer, Psychological Writings, 163); and the notion that rigorous logical training is a prerequisite for ethical excellence and happiness is essentially the theme of Errors of the Soul.

44 On the positive and negative effects of correct diet and exercise, on character, and on the intimate connection between medical lifestyle prescriptions and those 'for the soul' in a variety of its aspects-including participation in poetic or theatrical performance, and specific combat activities-see San. Tu. 1.7 (vi.31-32 K. = 16,1-5 Koch), 1.7 (VI.36-37 K. = 18,11-18 Koch), 1.8 (VI.39-44 K. = 19,14-21,20 Koch), 1.12 (vi.6o-61 K. = 28,22-29,5 Koch), 2.7 (VI.129-31 K. = 58,7-24 Koch). A mutually reinforcing relationship between body and soul factors is similarly suggested at $Q A M 11$ (v.821 K. = 79,2-9 Müller; on the text here see Singer, Psychological Writings, 408-9 and 424); and it is relevant in this context to consider the close connection between physical constitution and soul-qualities implied in Mixtures (Temp. 2.1 , I.576 K. = 42,16-20 Helmreich). There is also a particular focus on the educative value of music for the soul, especially the non-rational soul, in the passage 
As has been highlighted by Christopher Gill, Galen's perspective here seems heavily indebted to both the Platonic and the Aristotelian discourse on the importance both of early education and training and of subsequent habituation for ethical excellence. ${ }^{45}$

\section{Summary on Procedures 1-4}

If, then, we consider the relative role and prominence of these four procedures in the Galenic corpus, we find that they differ markedly in richness of information and style of exposition. It is striking that there seems to be more detail, as regards actual prescriptions for practice, in the admittedly short ethical opuscula (procedure 1) than in the works of disease classification and therapeutics. It is also striking that some of the most remarkable accounts of a doctor's successful intervention in medically-understood mental illness (those under our heading of procedure 2) are not accounts of Galen's own interventions, but taken from the tradition. The latter are not, in a sense, incorporated in the texts in which they appear: on the one hand, they are vivid narrative interludes within the argument of the text on the interpretation of a specific Hippocratic term; ${ }^{46}$ on the other, they give us a glimpse of some imagined possibilities, rather than anything like a systematic account. Turning to our procedure 3, there is little in Affected Places which gives detailed information on the treatment of brainrelated impairments - this in spite of its lengthy discussion of brain as locus of pathos, and its very detailed account of a number of different aetiologies, e.g. of melancholy. There is, admittedly, more detail in The Therapeutic Method; but even in this work of 'therapy' there is a great deal more material describing the pathology of such brain affections than describing its treatment, and what we do have does not amount to anything like a systematic account of the different treatments given for different brain affections. De symptomatum differentiis, too, offers some detailed pathology and classification of brain impairments, including vivid examples or 'case histories' (partially overlapping with those of Affected Places), but again without addressing the question of cure in

from Character Traits cited in the previous note. Relevant here too is the listing of the psychika pathe amongst six lifestyle factors relevant to health at both Ars Med. 23 (I.367 K. $=346,8-347,12$ Boudon) and Hipp. Epid. VI 8 (484,1-485,25 Pfaff), as discussed also by Christopher Gill in the present volume (375-77).

45 See Gill, Naturalistic Philosophy, 221-27, 249-50, 257-58, 261-62.

46 The 'case histories' cited above (nn. 25-26) occur in the context of two lengthy passages of Galenic exegesis, first of Hippocrates' mention of a range of mental indicators of pain in Epid. 2 (v.88,13-14 L.), and then of that of the single term gnōme, considered as causative of pathological states, in Epid. 6 (v.352,9 L.). 
any detail. There is, meanwhile, quite a large number of texts giving information on the humorally-based treatment of, e.g., phrenitis, lèthargos, melancholia and related illnesses, considering them as or within physical syndromes; and melancholia - or rather its adjectival cognate-is much more prominent here than in any psychological or psychotherapeutic contexts.

A little more needs to be said in relation to this last case, because at least some of the complaints described under 2 above are also defined as melancholic; this particular illness, or syndrome, thus appears in the two distinct therapeutic contexts. Does Galen then have a criterion of distinction between the two? Is there a clear principle explaining when one cures melancholia with cognitive therapy (or some other social intervention) and when with purgatives and blood-letting?

At an explicit level, the answer seems to be negative. Moreover, it is not always clear, in the cases under 2. above, what cognitive therapy if any is suggested. The terminology of 'melancholic' is used in relation to the man who fears that Atlas will drop the heavens. (It is not, I think, clear whether the delusions treated by various tricks in the cases mentioned in the Epidemics commentaries are also melancholic. ${ }^{47}$ ) Here, neither aetiology nor suggested treatment is clear. The occurrence of the case in similar form in Affected Places, in the context of a description of different forms of melancholia in physical terms, would suggest that Galen does here identify a physical aetiology (perhaps even a seasonally-related one, as in the case mentioned in n. 34 above), and thus attracting the usual purgative remedies. On the other hand, it is not clear whether it might not also attract such a remedy even if it did not have a physical aetiology.

In short, neither a distinction between psychogenic and physically caused forms of melancholia, nor a criterion of distinction between cases admitting of physical treatment and cases which may respond to some form of cognitive intervention, emerges with clarity from the texts.

To turn to our procedure 4 , finally - the preventive or educative approachthis is more difficult to summarize, because remarks relevant to the importance of diet, early education and ongoing discipline recur through a large number of Galen's writings. Although we have left it till last, this procedure is in a sense the most important: as is frequently asserted in both philosophical and dietetic contexts-and in contexts which represent an overlap between the two - good natural endowments, in conjunction with the correct forms of early training and habituation, are near-essential preconditions, of the avoidance both of physical ill health and —in the ethical domain—of succumbing 
to errors or affections. As already suggested, these propositions are emphasized and elaborated in De sanitate tuenda, in Character Traits and in The Soul's Dependence on the Body, as well as in Affections and Errors of the Soul and Freedom from Distress.

One might offer various analyses of this rather disparate and uneven material. One account of the data might be that, whereas with early diet and training, ongoing daily regime and the appropriate ethical interventions for people concerned to improve their behaviour (that is to say, the domains of 1 and 4 above), Galen is confident of his methods and of their possible success, when it comes to treatment of the medical pathè psychès there is less success, and less confidence. ${ }^{48} \mathrm{On}$ the other hand, it seems fair to make a distinction between the kinds of case summarized under 2 and those summarized under 3 . The latter, even though we have classified them for present purposes as 'mental', and even though they may involve impairment of rationality, can be seen, at least to a large extent, as short-lived and temporary, or as illnesses which present as episodes. This is true of phrenitis and its relatives (understood as related to fever), and of at least certain manifestations of mania; and, as we have seen, at least certain kinds of melancholia can be seen as seasonal, temporary and treatable by straightforward, physical therapies. In such cases, indeed, Galen seems confident of success.

The former may, by contrast, involve serious, long-term emotional disturbance or delusion, which is more problematic to eradicate (although it is also true, as we have just suggested, that the line of demarcation between cases mentioned under 2 and those mentioned under 3 is not always clear). And, certainly, it seems difficult to be confident, on the basis of the above, that Galen actually engaged in procedure 2 . The material which appears under our third heading, on the other hand, shows that there is a clearly established set of pharmaceutical-dietetic interventions for the medically-conceived affections of the soul-phrenitis, melancholia, lèthargos, etc.—involving for example applications to the head, and bloodletting. There is, however, very little detail on actual cases treated in this way; while it is possible that this lack of detail reflects paucity of actual experience in this area, conversely, as already discussed, the items in question are absorbed within a broader medical discourse, and it is also a possible interpretation that Galen does not dwell on case history here because it is, within his medical framework, no more noteworthy than

48 An interesting analysis in terms of the likely success, or lack of it, in Galen's interventions in this area, has been advanced by van der Eijk, P. 'Cure and (In)curability of Mental Disorders in Ancient Medical and Philosophical Thought', in Harris, W. V. (2013) Mental Disorders in the Classical World. Columbia Studies in the Classical Tradition 38, 307-38. 
any other instance of readjustment of the humours. It is, on either interpretation, striking that the experiential or psychologial side of such complaints seldom acquires any prominence.

\section{Text and Context}

At this point we should consider the genre and intended audience of the works in which the various passages considered above occur. But how much can be said with confidence about these? The situation is_-paradoxically, since Galen is primarily a medical author-somewhat clearer in his philosophical than in his medical works. Thus, while one may debate the precise genre of Affections and Errors of the Soul and Freedom from Distress, both clearly belong, broadly speaking, within a well-established existing tradition of works of popular moral philosophy - works which one might also term 'practical ethics' or 'selfimprovement', and which are exemplified in the surviving literature especially by Plutarch, Epictetus and Marcus Aurelius, and in Latin by Seneca. ${ }^{49}$

One reason for the comparative richness of the techniques described under approach 1 is, surely, precisely that they belong within this rich existing tradition: all the techniques which Galen mentions are exemplified, in fact more fully, in that tradition. Plutarch for example recommends the use of an ethical monitor (technique a), makes a strong parallel—as does Epictetus—between the use of words and medical interventions (b) and emphasizes the visual aspect (e) by suggesting use of a mirror to show the ugliness of one's ethical faults; and both the Pythagorean-style self-assessment and the praemeditatio malorum are well attested in this tradition too. ${ }^{50}$

49 See n. 2 above. More specifically on the genre of these works, see now the introductions to them by Boudon-Millot and Jouanna, Galien: Oeuvres 4 and in Singer, Psychological

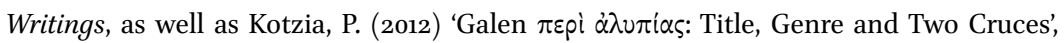
in Manetti, D. (2012) Studi sul De indolentia di Galeno, 69-91 (arguing against the identification of Ind. as a consolatio, despite some affinities, and pointing to the exsitence of a tradition of works peri alypias). We may say at least that the epistolary nature of Ind., and the plurality of addressees of Aff. Pecc. Dig. (purportedly the writing-up for a particular individual of a public speech, itself containing a further embedded response to a friend seeking advice: see Singer, Psychological Writings, 206-7), are central their generic self-presentation.

5o Fundamental studies in this area are Hadot, I. (1969) Seneca und die griechish-römische Tradition der Seelenleitung and Hadot, P. (1995) Philosophy as a Way of Life: Spiritual Exercises from Socrates to Foucault. For detailed parallels between the presentation of soul-therapy techniques in the Galenic texts and in this tradition of popular ethics, 
Central to this genre is that it is, precisely, a popularizing or self-help genre: the 'patient' is expected to make significant progress by following the instructions of the text-perhaps also, as suggested above, by attending public readings where similar material is spoken, directing his attention to the problems and to the importance of ethical progress. This is, in short, a discourse and a therapeutic process in which the lay person can and should be fully involved.

When we turn to the passages discussed under our third heading, the questions of genre and audience are more difficult. While this is not the place for a detailed discussion of the nature or function of Galen's or other medical authors' technical or paedagogic treatises,$^{51}$ some summary of the problem, focussing on the two works mainly considered above under this heading, The Therapeutic Method and Affected Places, will be helpful.

To take The Therapeutic Method first. On the one hand, the work is central to the curriculum of his works which Galen sets out both in My Own Books and in The Order of My Own Books. Indeed, it functions as a kind of marker in the curriculum: there is a defined set of books that need to be read before The Therapeutic Method, which then takes centre stage amongst the works devoted specifically to therapeutics. We then, in both auto-bibliographical works, get works related to prognosis and diagnosis, and Hippocratic commentaries. ${ }^{52}$ The Therapeutic Method seems-as indeed its length, as well as the frequency

see Singer, Psychological Writings, 207-17. See now also Xenophontos, S. (2016) Ethical Education in Plutarch: Moralising Agents and Contexts.

51 A very useful discussion of the question of Galen's audience and readership is Mattern, S. (2008) The Rhetoric of Healing, 14-21; see also the more detailed attempt to identify the addressee(s) and intellectual community relevant to a particular text by van der Eijk, P. 'Galen and the Scientific Treatise: A Case Study of Mixtures', in Asper, M. (2013) Writing Science: Medical and Mathematical Authorship in Ancient Greece, 145-76. Relevant too are the discussions of von Staden, H. 'Galen and the Second Sophistic', in Sorabji, R. (1997) Aristotle and After. Bulletin of the Institute of Classical Studies, Supplement 68, 33-54 and 'Staging the Past, Staging Oneself: Galen on Hellenistic Exegetical Traditions', in Gill, C., et al. (2009) Galen and the World of Knowledge, 132-56; König, J. 'Conventions of Prefatory Self-Presentation in Galen's On the Order of My Own Books', in ibid., 35-58; Boudon-Millot, V. 'Galen's bios and methodos: From Ways of Life to Path of Knowledge', in ibid., 175-89; Vegetti, M. (2013) Galeno: nuovi scritti autobiografici, esp. 31-48; Singer, P. N. 'New Light and Old Books: Galen on His Own Writings', in Petit, C. (forthcoming) A Tale of Resilience: Galen's Пвpi ¿̀ $\lambda \cup \pi i \alpha \varsigma$ (De indolentia) in Context.

$5^{2}$ See esp. Lib. Prop. 4-7 [3-4] (XIX.23-31 K. $=145^{-57}$ Boudon-Millot), a sequence which climaxes with the chapter titles 6 , 'Necessary to read before the therapeutic method ( $\tau \hat{\text { s }}$

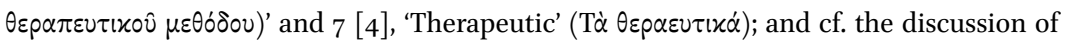
which works 'precede' and 'follow' the Therapeutic Method at Ord. Lib. Prop. 2 (94-95 Boudon-Millot). (The extent to which we have an order, from this point, rather just a list 
of its mention elsewhere in Galen's work, would also suggest - to represent a culmination: the clinical climax of a course of study which started with anatomy (or logic) and proceeded through physiology, element theory and disease classification before arriving finally at the practical outcome. Those mentions elsewhere in the corpus also support its central role in the curriculum: topics are typically referred to as "to be discussed" or "having been discussed" in The Therapeutic Method; and other works are described as laying the foundations for it. ${ }^{53}$

On the other hand, there is the denial that the work was intended for a wider audience, and, more than that, its explicit dedication to two named individuals, along with the explanation of a gap in its composition on the basis that the former individual had departed, leaving the author with no reason to complete the work. ${ }^{54}$

We may, of course, doubt the genuineness or historical reality of the sense in which any of Galen's works was written for a single individual, rather than either with a broader educational purpose or to increase his prestige more widely. A theoretical distinction can, however, be drawn between a group of works (including the vast majority of the medical ones) which Galen identifies as intended for his followers, and those for a wider audience, ${ }^{55}$ and it is surely the case, at least, that to dedicate a work either to a follower or followers, named or unnamed, was at once to put that work at the disposal of one's followers or students in general. The function of such a dedication to or mention of medical followers or students may, indeed, be that of identifying the work as a serious medical one rather than one for more general consumption. (It seems clear, in this connection, that both the Hiero and the Eugenianus to whom The Therapeutic Method is dedicated were medical followers of Galen. ${ }^{56}$ )

of remaining titles, is less than entirely clear; and, in spite of the titles, the ordering function is in general less clear in The Order of My Own Books than in My Own Books.). E.g. Temp. 2.6 (I.645 K. = 85,17-18 Helmreich).

$54 M M 1.1$ (X.1-2 K. = i.2 Johnston and Horsley); ibid. 7.1 (X.456-58 K. = ii.236-38 Johnston and Horsley).

55 See nn. 2, 50 above on differences in genre and audience.

$5^{6}$ See again $\mathrm{n} .5^{0}$ for fuller discussions; and in a forthcoming article on hetairoi in Galen, I aim to show (pace Mattern, Rhetoric, 14-16), that they are in fact a distinct class of medical disciples or 'followers'. Loc. Aff. mentions its purpose in training hetairoi (2.10, VIII.123 K. = 368,12-13 Gärtner); and the claim that major works, especially of anatomy, clinical medicine and Hippocratic commentary, were only written for unnamed hetairoi, is repeated throughout the corpus: see esp. MM 7.1 (X.456-58 K.); Hipp. Prog. 3 (XVIIIB.229-31 K. = 328,4-22 Heeg; Hipp. Epid. III 2 (XviIA.576-84 K. = 6o,4-66,7 Wenkebach); AA 5.6 (II.504-5 K.); SMT 6.1 (XI.894-95 K.). I suggest further that most named addressees of 
There remain considerable problems and complexities in this area. If, however, we may take it that both The Therapeutic Method and Affected Placesthe former with named recipients, the latter without-were in some sense written for students or medical followers, we are still left with the question: what kind of benefit?

Some features of these works seem extremely odd in relation to works intended for a student curriculum. One is the paucity of actual case histories; and this paucity, it should be noted, is not confined to the presentation of 'mental' cases, even if these seem particularly few (on this point see further below). Another is that both these works - to be more precise, the latter half of The Therapeutic Method and the whole of Affected Places - apparently belong to the period of Septimius Severus (193-99 CE), that is to say, to the latter end of Galen's career, his mid- to late sixties. In their final form, at least, these works could not have been of use to Galen's students during most of his teaching life. One might, it is true, go further, and point to the sense in which the entire medical curriculum of study outlined in My Own Books and The Order of My Own $B o o k s$ is a retrospective or imagined one. Yet a distinction must be made, here: on purely chronological grounds, this auto-anachronism seems to apply most especially precisely to these-apparently the most practical and clinically relevant of his writings. The vast body of works of anatomy, physiology, and even of prognosis and diagnosis (the pulse treatises, the works on fevers and crises), by contrast, seem to have been written up before $176 \mathrm{CE}$, and could in principle have formed part of the course of instruction followed by his students during the middle of Galen's career.

How, then, are we to explain either this special status of the major work of therapeutics or the fact that it was not important to complete its composition until so late in his career? A clue to the solution-and at the same time to that of the puzzling poverty of actual therapeutic detail in these works-is perhaps provided by some remarks made in both works regarding their genesis. At the beginning of book 7 , in explaining both his intention in writing The Therapeutic Method and the delay between books 6 and 7 , Galen says not just that the work was written in response to the request of a follower, but also that before its composition he had confined himself to writing down the information in summary form for his own benefit; and in the same passage he characterizes the work as fulfilling the request of many of his followers to have a written version

Galen's works are also such medical followers or students, dedication to a social superior or patron in Roman society (Boethus, Victorinus), by contrast, constituting exceptions. 
or reminder of the clinical practice which they have frequently observed. ${ }^{57}$ In Affected Places, meanwhile, as we saw in the extract from 3.10 on treatment of melancholics above, Galen reminds his students of cures that they have seen him apply in practice. That latter passage could hardly be taken to constitute a full description, let alone a practical manual, of Galen's therapeutic practice in response to different forms of melancholy; but it will serve the purposes both of outlining the major diagnostic differences and of reminding the student or practitioner of actual cures he has seen used in practice. A typology-a general characterization of the nature and key characteristics-is given. The precise knowledge of these cures, in terms of dosage, precise method of application, or of which to apply when, is not. That knowledge, presumably, is something that must be gained from practice.

The Therapeutic Method and Affected Places may, then, be seen as in some sense not texts of instruction, but as texts to accompany or remind one of instruction. ${ }^{58}$ This raises the question of the relationship between text and active medical teaching in Galen's period. This is a difficult and problematic area. On one interpretation, Galen's specialist writings, especially those in the diagnostic-clinical area, belong within a discourse which elevates the author's expert status, giving a virtuoso intellectual display while simultaneously

$57 \quad M M 7.1$ (X.458 K. = ii.238 Johnston and Horsley). The term $\dot{\pi} \pi \mu \nu \nu \dot{\mu} \mu \alpha \tau \alpha$, used in this passage to refer to such a written record, can admittedly have a very wide application in relation to written works; but here the original sense of "reminder" or aide-mémoire seems to be to the fore.

$5^{8}$ In fact, this role in reminding, or providing notes of, previous oral instruction is explicitly highlighted, in the passages cited in $n .5^{6}$ above: that the hetairoi, especially those who are travelling abroad, need some record of what was said in anatomical demonstrations or clinical contexts is precisely the reason for the texts being 'given' to them. The reminder function also arguably explains another feature which seems otherwise inexplicable in works intended for Galen's close followers: the space given to general principles and to polemic against rivals. In a specialist work, one might think, Galen's students need no instruction in the wrongness of the views of Thessalus and the Methodists, of the absurdity of Archigenes' error in stating that the leading-faculty of the soul resides in the heart, or, indeed, of the exalted status of the art of medicine in general. Here, then, the reminder that the texts provide may be understood as relating not primarily to theory, to diagnosis or to therapy, but to the way to proceed in argument against certain opponents. They would, in this sense, be handbooks as much of medical rhetoric, of public medical instruction, as of medical practice. If such an idea seems to us bizarre, it should be remembered that some such function for his own texts is explicitly envisaged by Galen. At Lib. Prop., praef. (XIX.14 K. = 139,2-9 Boudon-Millot) he states that certain of his works were requested by his followers as the basis for demonstration, indeed explicitly for the public refutation of others. 
withholding the detailed knowledge necessary for practice: both student and lay reader must always defer to the uniqueness of that expertise. ${ }^{59}$ One might, alternatively, draw attention to the fact, emphasized by Galen himself, that empirical observation and the training of one's own faculties are essential for the practising clinician - a fact which again points to the inadequacy of the treatise, taken on its own, to provide clinical instruction. Either interpretation, however, suggests a limitation to the function of these texts: they are not 'doit-yourself' guides. And that, in a sense, marks out a difference between them and the short ethical works.

Galen's procedure in such texts-those of disease classification and especially those of therapeutics - is to spend a long time on fundamental conceptual issues, on methodology, on broad diagnostic categories, but to deal with actual clinical practice only by way of a few indicative examples. The poverty, or rather the very selective nature, of the practical therapeutic details, is thus a function of the nature of these texts and their position in relation to instruction: to this extent, it is a feature of Galen's presentation of clinical methods in general, and not one confined to their presentation in the specific context of the mental.

It is relevant here to consider Galen's attitude to 'case histories' more generally. Galen has an explicit theoretical view here, related to his use of the term historia - a term with a specific doctrinal sense within Empiricist medicine. There, historia, in conjunction with 'experience' and 'transition to the similar', is sufficient for medical practice. Galen rejects that intellectual tradition and is, relatedly, suspicious of excessive time spent on recounting the details of particular cases: this may appear like the 'mere' accumulation of historiai. ${ }^{60}$ So, historiai may be mentioned where they exemplify an important conceptual point or diagnostic distinction. They may also, of course, serve to publicize Galen's success in mastering such diagnostic distinctions; and that self-publicizing purpose, too, is an important aspect of the genre of certain texts-in particular of Prognosis, where, as we have seen, it helps to explain the partial

59 See the analysis of specialist texts of medical prognosis in the context of other scientific knowledge claims in the Graeco-Roman world by Barton, T. S. (1994) Power and Knowledge: Astrology, Medicine, and Physiognomics under the Roman Empire.

$60 \quad$ See Galen, Subfiguratio 3 (48-49 Deichgräber); sI 2 (I.67 K. = 3 Helmreich); Hipp. Epid. III 2 (XVIIA.617 K. = 85,20-22 Wenkebach); AA 7.13 (II.632 K.); and Hipp. Prog. 1.4 (XVIIIB.17

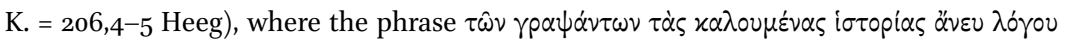
seems to be an attack on some such process of writing up un-theorized case histories. On Galen's attitude to the case history, and it subordinate role to theory in his writings, see Lloyd, G. E. R. 'Galen's Un-Hippocratic Case Histories', in Gill et al. (2009) Galen and the World of Knowledge, $115-31$. 
nature of the 'case history' information given there. But individual cases are not - theoretically — of value in their own right; and although, from the reader's point of view, they often provide the most vivid and interesting information about ancient medical practice, the doctor-patient encounter, and even other aspects of everyday life, from the author's 'offical' point of view they play a very subordinate role in the exposition.

\section{Final Considerations}

These textual aspects, then, and the fact, already discussed, that Galen seems more interested in demonstrating his diagnostic than his therapeutic success, may provide a better explanation for the paucity of psychological therapeutic cases - and indeed for the fact that such cases are not always his own - than the (ultimately irretrievable) historical realities of his daily practice. One must also, however, do justice to the interpretation which points to Galen's comparative lack of interest in psychological experience within pathology, and in terms of his tendency to understand psychopathology largely within the framework of physical syndromes.

I offer a final perspective on the amount of material in Galen's work relevant to the treatment of mental disturbance. Susan Mattern's table of 'case histories' described throughout the Galenic corpus lists a total of $358 .{ }^{61}$ Within that number, I reckon the total which could be placed under the heading of mental illness or disturbance as 37-and some of those 37 are repetitions of the same case. This figure does not include those cases of soul affection-anger and distress-which we have seen in the shorter ethical works. It does include both epilepsy and cases of paraphrosyne (delirium or derangement) accompanying fever: indeed these two predominate. It also includes the female complaints presented under the heading 'hysterical'; those curious 'case histories' from his commentaries on the Epidemics which we have seen to derive at least in part from the previous tradition; and the cases (both in the Epidemics commentaries and in Prognosis) where love is the underlying cause of the complaint. (Incidentally, the two works which we have particularly considered, Affected Places and The Therapeutic Method, between them provide nearly half that total of $35^{8}$ case histories; within these texts, those that may be classified as 'mental' amount, respectively, to ten and two.) If we then consider, within our short list of 'mental' case histories, those where Galen describes an actual

61 Mattern, Rhetoric, 173-202. 
treatment, the total is something like seven-this including those treatments which we have noted him to be recounting from that previous tradition.

We have suggested that the complex situation which we find within the Galenic corpus, in relation to mental illness and/or emotional disturbance, may be interpreted partly as a function of the complex interaction of Galen's models of the $p s y c h \bar{e}$ and of the variety of traditions and types of practical intervention used by him, and partly as a function of the varied nature, genre and purpose of the Galenic texts. To summarize that complex situation:

(1) there is no work of Galen's dedicated to the medical psychic impairments (as opposed to the ethical pathē psychēs); rather, the most relevant material occurs in passing in the context of other discussions, e.g. of the fact that the brain is the seat of the leading-faculty, of the nature of primary and secondary affection of organs, or of the distinction between hot and cold illnesses;

(2) such terms as mania, melancholia, and their cognates occur predominantly in accounts of disease conceptualized in physical (humoral) terms, as part of physical syndromes, with little concern for their experiential dimension;

(3) the texts which describe the ethical pathē psychēs give a fuller, and more easily summarizable, theoretical and therapeutic framework than the medical ones, where the material is by contrast spread piecemeal over the corpus, and presented in a variety of different theoretical contexts;

(4) in medical texts which do describe the medical psychic impairments, disease classification and diagnosis predominate considerably over treatment, although there is certainly some information about how treatments were applied;

(5) in general, the dietetic, preventive and ethical approach to the soul's disturbances is more clearly and consistently described than the medical;

(6) the most arresting and vivid examples of serious mental distress or delusion which Galen describes in detail are presented to us either without any mention of treatment or with reference to interventions attributed to doctors in the tradition previous to Galen.

We have considered in some detail the picture of 'mental illness' that emerges from Galen. It is a complex picture, and Galen is in some respects a special case. Yet it is a picture which-for all the complexity-offers the viewer perhaps an appropriate closing tableau, in a narrative of mental illness in the Graeco-Roman world. It reflects and summarizes the major themes which we have seen play themselves out, in different—and also in complex-ways, in 
the texts of Galen's main predecessors, contemporaries and followers in the imperial period. In particular: the extent to which the understanding of mental illness is or is not incorporated in physicians' medical theories, diagnostic, physiological and anatomical; the contexts and ways in which disorders 'of the soul' enjoy a special status in Graeco-Roman thought; the interaction of specialist medical with broader societal or 'lay' attitudes to such disturbances; the variety of interventions that they attract, from pharmacological and surgical, through dietetic and environmental, to cognitive; above all, the complex interaction of medical and philosophical arguments and techniques that are engaged in the approach to all these questions. 